\title{
Synthesis and Anti-proliferative Activity of 4H-Chromone Based Phenylhydrazones, Pyrazolecarboxylates and Pyrazolylmethanones
}

\author{
Nageswara Rao Rayala, ${ }^{1}$ Rajkumar Kommera, ${ }^{1}$ Dayakar Cherupally, ${ }^{1}$ \\ Ramalinga Murthy Thampunuri, ${ }^{2}$ V. Kalivendi Shasi ${ }^{2}$ and China Raju Bhimapaka ${ }^{1, \star}$ \\ ${ }^{1}$ Natural Products Chemistry Division, \\ ${ }^{2}$ Chemical Biology Division, \\ CSIR-Indian Institute of Chemical Technology, Hyderabad-500 007, India. \\ * Corresponding author: E-mail: chinaraju@iict.res.in \\ Tel: +91-40-27191725; Fax: +91-40-27160512
}

Received: 18-04-2017

\begin{abstract}
Series of $4 H$-chromone-based hydrazones $3 \mathbf{a}-\mathbf{z}$, pyrazolecarboxylates $\mathbf{5 a}-\mathbf{x}$ and pyrazolylmethanones $\mathbf{6 a}-\mathbf{u}$ were prepared and screened for their anti-proliferative activity on A549, HeLa, DU145 and MDAMB 231 cell lines. The hydrazone compound $3 \mathrm{~s}$ with a chloro substituent on the chromanone moiety and a methoxy group on the phenyl ring displayed promising activity on A549, HeLa and DU145 cell lines. The compound 5p with a bromo substituent on the chromanone moiety and a methyl group on the phenyl ring displayed potent activity on DU145. Furopyrazolecarboxylate $5 \mathbf{w}$ having a methyl substituent on the phenyl ring displayed potent activity on HeLa cell line. The pyrazolylmethanone $6 \mathbf{e}$ with a fluoro substituent on the phenyl ring and compound $\mathbf{6 j}$ having a methyl substituent on the chromanone moiety and a methoxy group on the phenyl ring have shown promising anti-proliferative activity on HeLa cell line.
\end{abstract}

Keywords: 3-Formylchromones, pyrazolecarboxylates, pyrazolylmethanones, cycloaddition, anti-proliferative activity.

\section{Introduction}

Hydrazones, pyrazoles and pyrazolylmethanones are important heterocyclic compounds. ${ }^{1}$ The hydrazone-containing compounds obtained from carboxaldehydes with hydrazines have been shown to exhibit a variety of biological and pharmacological activities, ${ }^{2-5}$ namely antimicrobial, anti-inflammatory, anti-tumor and anti-tubercular. Celebrex and Sildenafil are the pyrazole-based potent drug molecules. Celebrex is a COX-2 selective non-steroidal anti-inflammatory drug used to treat the pain and inflammation. ${ }^{6}$ Sildenafil is a pharmaceutical drug used to treat erectile dysfunction. ${ }^{7}$ Pyrazolylmethanones prepared by the reduction of carboxaldehydes were found to be anti-microbial and anti-inflammatory agents. ${ }^{8}$

In the course of our efforts in discovery and identification of biologically active compounds, ${ }^{9-12}$ we focused research on 3-formylchromones and prepared series of $4 H$-chromen-1,2,3,4-tetrahydropyrimidine-5-carboxylates. ${ }^{13}$ Further, pyridine, pyridone and benzopyridocarbox- ylates were reported by three-component, one-pot reaction of 3-formylchromones, benzylamines, 2-aminophenols with 3-oxobutanoates. ${ }^{14}$ The present manuscript describes the preparation of 3-formylchromone-based hydrazones, pyrazolecarboxylates, pyrazolylmethanones and their anti-proliferative activity.

\section{Results and Discussion}

\section{1. Preparation of $(E)-3-((2-$ Phenylhydrazono)methyl)-4H-chromen- 4-ones 3a-z}

Schemes 1-3 describe the preparation of target compounds $\mathbf{3 a}-\mathbf{z}$ starting from 3 -formylchromones $\mathbf{1}$. The required 3-formylchromones 1a-f were prepared as per our earlier reported method. ${ }^{13}$ Condensation of 3-formylchromones $\mathbf{1 a}-\mathbf{d}$ with phenylhydrazine hydrochlorides $\mathbf{2 a}-\mathbf{i}$ in the presence of acetic acid in methanol at $60^{\circ} \mathrm{C}$ provided 
<smiles>[R]c1ccc2occ(C=O)c(=O)c2c1</smiles><smiles>[R]c1ccc2occ(/C=N/Nc3ccc([R1])c([R])c3[R1])c(=O)c2c1</smiles>

$$
\begin{array}{ll}
\text { 1a } R=H & \text { 2a } R^{1}=H, R^{2}=H, R^{3}=H \\
\text { 1b } R=C_{3} & \text { 2b R } R^{1}=H, R^{2}=C H_{3} R^{3}=H \\
\text { 1c } R=C l & \text { 2c } R^{1}=H, R^{2}=H, R^{3}=\mathrm{OCH}_{3} \\
\text { 1d } R=B r & \text { 2d } R^{1}=F, R^{2}=H, R^{3}=H \\
& \text { 2e R } R^{1}=H, R^{2}=F, R^{3}=H \\
& \text { 2f } R^{1}=H, R^{2}=C l, R^{3}=H \\
& \text { 2g R } R^{1}=H, R^{2}=H, R^{3}=F \\
& \text { 2h R } R^{1}=H, R^{2}=H, R^{3}=B r \\
& \text { 2i } R^{1}=C l, R^{2}=H, R^{3}=C l
\end{array}
$$

Scheme 1. Preparation of hydrazones $3 \mathbf{a}-\mathbf{v}$

the corresponding hydrazones $\mathbf{3 a} \mathbf{a}-\mathbf{v}$ as yellow color solids (Scheme 1, Table 1). The compounds $\mathbf{3 a}, \mathbf{3 j}$ and $\mathbf{3 t}$ are known and were compared with the literature data. ${ }^{15-18}$ The compounds $\mathbf{3 b}-\mathbf{i}, \mathbf{3 k}-\mathbf{s}$ and $\mathbf{3 u}-\mathbf{z}$ are unknown and were well characterized by spectral data.

Schemes 2 and 3 describe the preparation of linear and angular furo hydrazones $3 \mathbf{w}-\mathbf{z}$. The carboxaldehydes le,f was prepared as per our previous reported method. ${ }^{13}$
Condensation of carbaldehydes $\mathbf{1 e}, \mathbf{f}$ with phenylhydrazine hydrochlorides $\mathbf{2} \mathbf{a}, \mathbf{b}$ provided the hydrazones $\mathbf{3} \mathbf{w}-\mathbf{z}$ (Table 1).

\section{2. Preparation of Pyrazolecarboxylates $5 a-x$}

Schemes 4-7 describe the preparation of pyrazolecarboxylates $\mathbf{5} \mathbf{a}-\mathbf{x}$ by cycloaddition reaction of hydrazones<smiles>O=Cc1coc2cc3occc3cc2c1=O</smiles>

1e<smiles>[R]c1ccc(NN)c([R])c1[R]</smiles><smiles>CCOC(=O)OC</smiles>

$R^{1}=R^{2}=R^{3}=H$

2b R $R^{1}=\mathrm{H}, \mathrm{R}^{2}=\mathrm{CH}_{3}, \mathrm{R}^{3}=\mathrm{H}$<smiles>[R]c1ccc(N/N=C/c2coc3cc4occc4cc3c2=O)c([R])c1[R]</smiles>

$3 w-x$

Scheme 2. Preparation of hydrazones $3 \mathbf{w}-\mathbf{x}$<smiles>O=Cc1coc2c(ccc3occc32)c1=O</smiles><smiles>[R]c1ccc(NN)c([R])c1[R]</smiles><smiles>[R]c1ccc(N/N=C/c2coc3c4c(ccc3c2=O)OCC4)c([R])c1[R]</smiles>

2a $R^{1}=R^{2}=R^{3}=H$

2b R $\mathbf{R}^{1}=\mathrm{H}, \mathrm{R}^{2}=\mathrm{CH}_{3}, \mathrm{R}^{3}=\mathrm{H}$

Scheme 3. Preparation of hydrazones $3 y-z$<smiles>O=c1c(/C=N/Nc2ccccc2)coc2ccccc12</smiles>

$3 a$

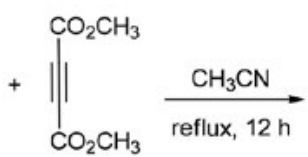

$4 a$<smiles>COC(=O)c1c(C(C)=O)c(-c2coc3ccccc3c2=O)nn1-c1ccccc1</smiles>

5 a<smiles>O=C(c1cnn(-c2ccccc2)c1)c1ccccc1O</smiles>

6a

Scheme 4. Preparation of pyrazolecarboxylate 5a 
and activated alkynes. Initially, the cycloaddition reaction has been conducted with hydrazone $\mathbf{3 a}$ and acetylenedicarboxylate $\mathbf{4 a}$ in acetonitrile as the solvent under reflux conditions. This reaction provided two compounds, pyrazolecarboxylate 5a and pyrazolylmethanone 6a (Scheme 4 ). These two compounds were separated by column chromatography and characterized by spectral data.

In order to prepare the compound $\mathbf{5 a}$ in an exclusive manner, bromination reaction has been carried out on $\mathbf{3 a}$ with $\mathrm{N}$-bromosuccinimide (NBS) in carbon tetrachloride at $55-60{ }^{\circ} \mathrm{C}$. The reaction was monitored by TLC $(3-4 \mathrm{~h})$ and the usual workup afforded the corresponding $\boldsymbol{\alpha}$-bromophenylhydrazonochromone.${ }^{19}$ Next, the $[3+2]$ cycloaddition reaction have been conducted between $\boldsymbol{\alpha}$-bromophenylhydrazonochromone and acetylenedicarboxylates $\mathbf{4 a}-\mathbf{b}$ in the presence of triethylamine. This provided the corresponding pyrazolecarboxylates $\mathbf{5 a}$ and $\mathbf{5 r}$. In order to prepare series of pyrazolecarboxylates $\mathbf{5}$, the bromination and cycloaddition reactions have been carried out on hydrazones $\mathbf{3 b}-\mathbf{c}, \mathbf{3 e}, \mathbf{3 h}-\mathbf{l}, \mathbf{3 n}$ and $\mathbf{3 p}-\mathbf{v}$ with $\mathbf{4 a}$ to provide a set of pyrazolecarboxylates $\mathbf{5 b}-\mathbf{q}$ (Scheme 5 , Table 2 ). The compound $\mathbf{5 a}$ is known and was compared with the literature data. ${ }^{19}$ Compounds $\mathbf{5 b}-\mathbf{r}$ are new and were well characterized by spectral data.

Having achieved the pyrazolecarboxylates, further the preparation of linear and angular pyrazolecarboxylates $\mathbf{5 s - \mathbf { x }}$ has been planned. Accordingly, the bromination followed by cycloaddition reaction have been carried out with hydrazones $3 \mathbf{w}-\mathbf{z}$ and activated alkynes $4 \mathbf{a}-\mathbf{b}$ to provide corresponding pyrazolecarboxylates $\mathbf{5 s}-\mathbf{x}$ (Schemes 6 and 7 , Table 2). The compounds $\mathbf{5 s}-\mathbf{x}$ are unknown and were well characterized by spectral data.

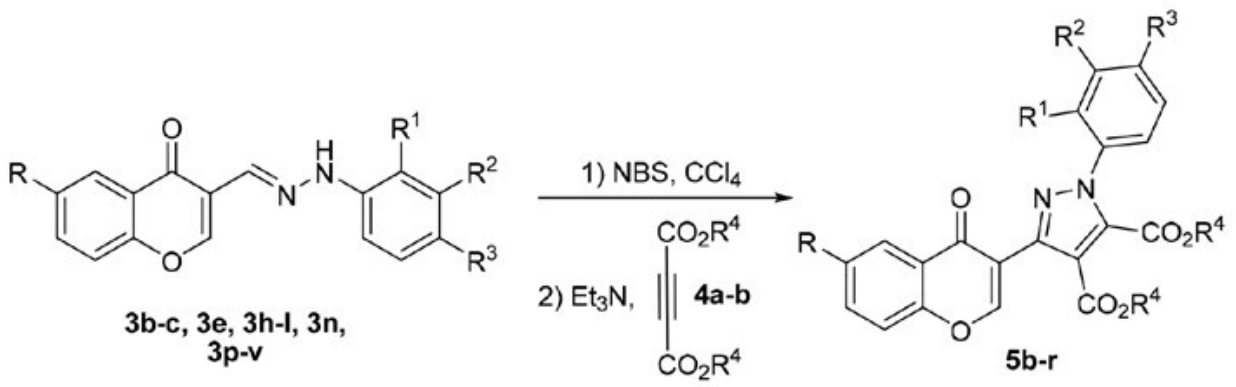

Scheme 5. Preparation of pyrazolecarboxylates $5 \mathbf{b}-\mathbf{r}$

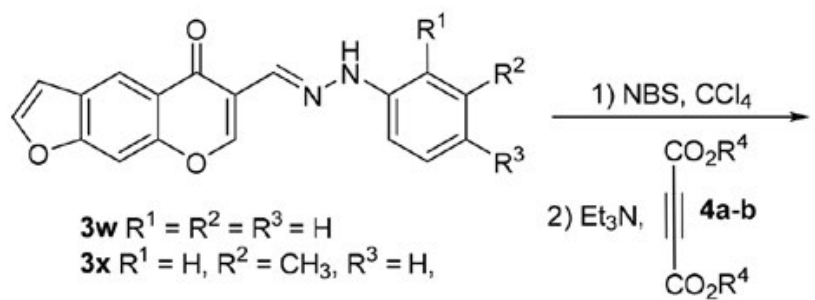

Scheme 6. Preparation of linear furochromenyl pyrazolecarboxylates 5s-u

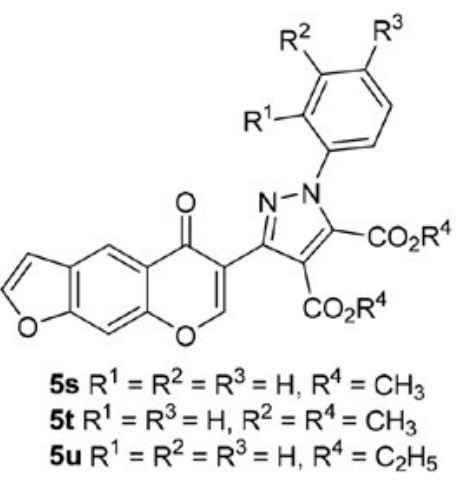

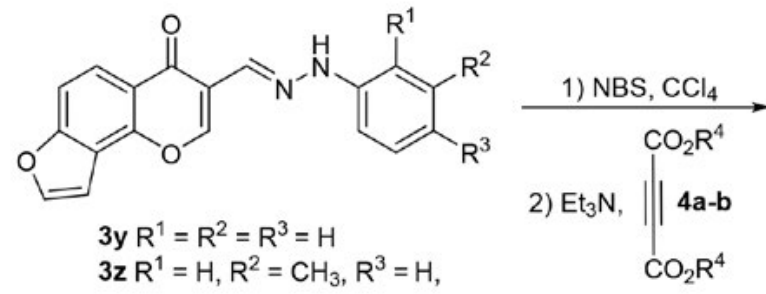

3y $\mathrm{R}^{1}=\mathrm{R}^{2}=\mathrm{R}^{3}=\mathrm{H}$

$3 \mathbf{z} \mathbf{R}^{1}=\mathrm{H}, \mathrm{R}^{2}=\mathrm{CH}_{3}, \mathrm{R}^{3}=\mathrm{H}$,

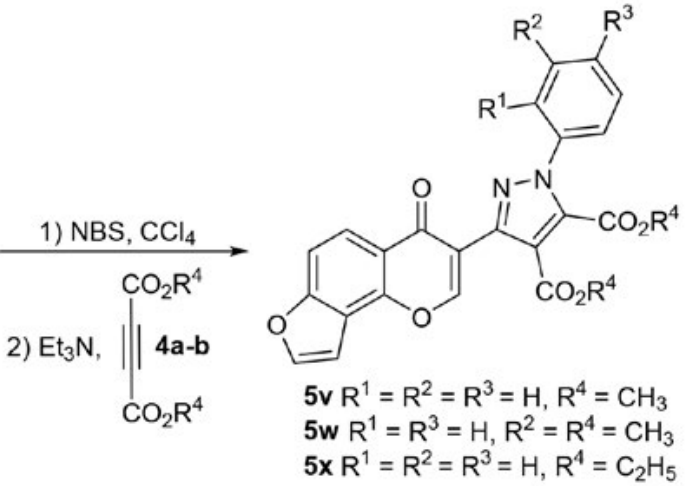

Scheme 7. Preparation of angular furochromenyl pyrazolecarboxylates $5 \mathbf{v}-\mathbf{x}$ 


\section{3. Preparation of pyrazolylmethanones 6a-u}

The cycloaddition reaction of hydrazone $\mathbf{3 a}$ with acetylenedicarboxylate $\mathbf{4 a}$ provided two compounds, pyrazolecarboxylate $\mathbf{5 a}$ and pyrazolylmethanone $\mathbf{6 a}$ Scheme 4. The pyrazolylmethanone compound $\mathbf{6 a}$ is known in the literature, however, the development of synthetic procedures for these molecules and their biological properties are not well established, yet. Therefore, a series of pyrazolylmethanones $\mathbf{6 b}-\mathbf{u}$ have been prepared by the reaction of hydrazones $\mathbf{3 a}-\mathbf{h}, \mathbf{3 k}-\mathbf{s}, \mathbf{3} \mathbf{u}-\mathbf{x}$ with $\mathrm{K}_{2} \mathrm{CO}_{3}$ in acetonitrile at room temperature (Schemes 8 and 9, Table 3). The known compound $\mathbf{6 a}$ was compared with the literature data $^{20}$ and the unknown compounds $\mathbf{6 b}-\mathbf{u}$ are were well characterized by spectral data.

\section{Biology}

Thus synthesized hydrazones $\mathbf{3 a}-\mathbf{z}$, pyrazolecarboxylates $\mathbf{5} \mathbf{a}-\mathbf{x}$ and pyrazolylmethanones $\mathbf{6 a}-\mathbf{u}$ were screened for their anti-proliferative activity against four cancer cell lines, viz. A549 (lung), HeLa (cervical), DU145 (prostate), MDA MB 231 (breast) by MTT assay. ${ }^{13}$

\section{1. Anti-proliferative Activity of Hydrazones $3 a-z$}

The anti-proliferative activity of hydrazones and their $\mathrm{IC}_{50}$ values along with standard drug doxorubicin are presented in Table 1 . The compounds $\mathbf{3 a}-\mathbf{i}$ displayed activity in the range of $\mathrm{IC}_{50} 46.0-170.1 \mu \mathrm{M}$ in all the tested cell lines. The presence of a methyl group on the chromanone moiety and a halogen, methyl and methoxy substituents on the phenyl ring in $\mathbf{3} \mathbf{j}-\mathbf{p}$ displayed activity in the range of $\mathrm{IC}_{50} 41.2-494.7 \mu \mathrm{M}$ in all the tested cell lines. The presence of halogens on chromanones and a methyl or a methoxy group on the phenyl ring in $\mathbf{3 q}-\mathbf{v}$ displayed activity in the range of $\mathrm{IC}_{50} 14.0-355.5 \mu \mathrm{M}$ in all the tested cell lines. However, compound $3 \mathbf{s}$ (IC $_{50}$ $19.7,14.0,17.8 \mu \mathrm{M})$ has shown promising activity on A549, HeLa and DU145, respectively. The linear 3w-x and angular $\mathbf{3 y - z}$ furo chromanones showed activity in the range of $\mathrm{IC}_{50} 42.1-183.7 \mu \mathrm{M}$ in all the tested cell lines.

\section{2. Anti-proliferative Activity of Pyrazolecarboxylates 5a-x}

The anti-proliferative activity of pyrazolecarboxylates $\mathbf{5 a}-\mathbf{x}$ and their $\mathrm{IC}_{50}$ values along with the data for the standard drug are presented in Table 2 . The compound $\mathbf{5 d}$ $\left(\mathrm{IC}_{50} 24.0 \mu \mathrm{M}\right.$ ) having a fluoro substituent on the phenyl ring has shown better activity on A549 when compared to the methyl $\mathbf{5 b}$, methoxy $\mathbf{5 c}$, bromo $\mathbf{5 e}$ and chloro $\mathbf{5 f}$ derivatives. The methyl substituted chromanones $\mathbf{5 g}\left(\mathrm{IC}_{50}\right.$ $13.0 \mu \mathrm{M})$ and $\mathbf{5 h}\left(\mathrm{IC}_{50} 19.0 \mu \mathrm{M}\right)$ displayed promising activity on HeLa and DU145, respectively when compared to $5 \mathbf{i}-\mathbf{k}$. The bromo substituted chromanone with a methyl group $5 \mathbf{p}\left(\mathrm{IC}_{50} 5.0 \mu \mathrm{M}\right)$ or a methoxy group $\mathbf{5 q}\left(\mathrm{IC}_{50}\right.$ $11.0 \mu \mathrm{M})$ on the phenyl ring displayed the potent activity. Chloro substituted chromanone $5 \mathrm{~m}\left(\mathrm{IC}_{50} 24.0 \mu \mathrm{M}\right)$ displayed better activity on DU145 when compared to the corresponding methoxy derivative $\mathbf{5 n}$. The angular furo derivative $5 \mathrm{w}\left(\mathrm{IC}_{50} 5.0 \mu \mathrm{M}\right)$ has shown potent activity on HeLa and promising activity on DU145 $\left(\mathrm{IC}_{50} 15.0 \mu \mathrm{M}\right)$ when compared to the corresponding linear furo derivative $5 \mathbf{t}$.<smiles>[R]c1ccc2occ(/C=N/Nc3ccc([R])c([R])c3[R])c(=O)c2c1</smiles><smiles>[R]c1ccc(O)c(C(=O)c2cnn(-c3ccc([R])c([R])c3[R])c2)c1</smiles>

Scheme 8. Preparation of pyrazolylmethanones 6a-s

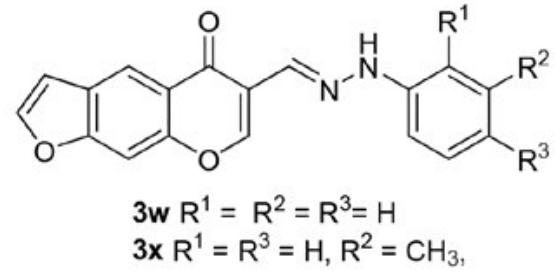
$3 x R^{1}=R^{3}=H, R^{2}=C_{3}$,<smiles>[R]c1ccc(-n2cc(C(=O)c3cc4cc(C(=O)OCC)oc4cc3O)cn2)c([R])c1[R]</smiles>
reflux $12 \mathrm{~h}$

Scheme 9. Preparation of linear pyrazolylmethanones $6 \mathbf{t}-\mathbf{u}$ 
Table 1. Anti-proliferative activity of hydrazones*

\begin{tabular}{|c|c|c|c|c|c|c|c|c|}
\hline Compounds & $\mathbf{R}$ & $\mathbf{R}^{1}$ & $\mathbf{R}^{2}$ & $\mathbf{R}^{3}$ & A549 & HeLa & DU145 & MDA MB 231 \\
\hline $3 \mathbf{a}$ & $\mathrm{H}$ & $\mathrm{H}$ & $\mathrm{H}$ & $\mathrm{H}$ & $170.1 \pm 8.4$ & $48.5 \pm 2.9$ & $91.1 \pm 3.8$ & $78.2 \pm 3.1$ \\
\hline $3 b$ & $\mathrm{H}$ & $\mathrm{H}$ & $\mathrm{CH}_{3}$ & $\mathrm{H}$ & $70.6 \pm 5.1$ & $151.7 \pm 7.8$ & $57.4 \pm 2.6$ & $58.3 \pm 4.5$ \\
\hline $3 c$ & $\mathrm{H}$ & $\mathrm{H}$ & $\mathrm{H}^{3}$ & $\mathrm{OCH}_{3}$ & $69.7 \pm 3.9$ & $63.5 \pm 4.5$ & $101.9 \pm 5.8$ & $85.4 \pm 3.9$ \\
\hline $3 d$ & $\mathrm{H}$ & $\mathrm{F}$ & $\mathrm{H}$ & $\mathrm{H}^{3}$ & $77 \pm 4.8$ & $72.3 \pm 6.4$ & $82.8 \pm 6.8$ & $69.1 \pm 3.9$ \\
\hline $3 e$ & $\mathrm{H}$ & $\mathrm{H}$ & $\mathrm{F}$ & $\mathrm{H}$ & $66.2 \pm 2.8$ & $77.4 \pm 4.9$ & $50.7 \pm 2.4$ & $85.6 \pm 6.4$ \\
\hline $3 f$ & $\mathrm{H}$ & $\mathrm{H}$ & $\mathrm{Cl}$ & $\mathrm{H}$ & $46 \pm 2.5$ & $84.5 \pm 6.7$ & $59.2 \pm 2.9$ & $156.9 \pm 11.5$ \\
\hline $3 g$ & $\mathrm{H}$ & $\mathrm{H}$ & $\mathrm{H}$ & $\mathrm{F}$ & $49.7 \pm 2.1$ & $67.9 \pm 3.8$ & $84 \pm 3.1$ & $87.3 \pm 4.5$ \\
\hline $3 \mathrm{~h}$ & $\mathrm{H}$ & $\mathrm{H}$ & $\mathrm{H}$ & $\mathrm{Br}$ & $46.4 \pm 4.6$ & $104.7 \pm 8.3$ & $56.8 \pm 2.7$ & $154.2 \pm 9.7$ \\
\hline $3 \mathbf{i}$ & $\mathrm{H}$ & $\mathrm{Cl}$ & $\mathrm{H}$ & $\mathrm{Cl}$ & $80.5 \pm 6.1$ & $128.2 \pm 8.5$ & $80.4 \pm 2.5$ & $124.3 \pm 9.4$ \\
\hline $3 \mathbf{j}$ & $\mathrm{CH}_{3}$ & $\mathrm{H}$ & $\mathrm{H}$ & $\mathrm{H}$ & $63.3 \pm 3.4$ & $164.6 \pm 9.8$ & $102.3 \pm 8.9$ & $157.2 \pm 9.5$ \\
\hline $3 \mathbf{k}$ & $\mathrm{CH}_{3}^{3}$ & $\mathrm{H}$ & $\mathrm{CH}_{3}$ & $\mathrm{H}$ & $76.6 \pm 3.4$ & $77.7 \pm 4.8$ & $91.4 \pm 3.4$ & $112.5 \pm 7.9$ \\
\hline 31 & $\mathrm{CH}_{3}^{3}$ & $\mathrm{H}$ & $\mathrm{H}^{3}$ & $\mathrm{OCH}_{3}$ & $80.2 \pm 3.9$ & $494.7 \pm 13.2$ & $103.2 \pm 4.9$ & $345.6 \pm 16.7$ \\
\hline $3 \mathrm{~m}$ & $\mathrm{CH}_{3}$ & $\mathrm{~F}$ & $\mathrm{H}$ & $\mathrm{H}$ & $41.2 \pm 1.3$ & $101.6 \pm 8.7$ & $46.7 \pm 3.8$ & $68.3 \pm 3.5$ \\
\hline $3 n$ & $\mathrm{CH}_{3}^{3}$ & $\mathrm{H}$ & $\mathrm{F}$ & $\mathrm{H}$ & $92.5 \pm 5.4$ & $48 \pm 2.1$ & $93.5 \pm 2.7$ & $91.5 \pm 4.1$ \\
\hline 30 & $\mathrm{CH}_{3}^{3}$ & $\mathrm{H}$ & $\mathrm{H}$ & $\mathrm{F}$ & $63.1 \pm 3.4$ & $68.5 \pm 6.7$ & $80 \pm 3.4$ & $76.5 \pm 6.8$ \\
\hline $3 p$ & $\mathrm{CH}_{3}$ & $\mathrm{H}$ & $\mathrm{H}$ & $\mathrm{Br}$ & $73.7 \pm 6.1$ & $58.2 \pm 4.4$ & $152.1 \pm 10.2$ & $225.3 \pm 9.8$ \\
\hline $3 q$ & $\mathrm{Cl}^{3}$ & $\mathrm{H}$ & $\mathrm{H}$ & $\mathrm{H}$ & $52.2 \pm 2.8$ & $75 \pm 5.1$ & $355.5 \pm 12.1$ & $312.2 \pm 18.4$ \\
\hline $3 \mathbf{r}$ & $\mathrm{Cl}$ & $\mathrm{H}$ & $\mathrm{CH}_{3}$ & $\mathrm{H}$ & $45.1 \pm 4.8$ & $53.9 \pm 4.1$ & $48.1 \pm 3.5$ & $78.5 \pm 2.7$ \\
\hline $3 s$ & $\mathrm{Cl}$ & $\mathrm{H}$ & $\mathrm{H}^{3}$ & $\mathrm{OCH}_{3}$ & $19.7 \pm 2.1$ & $14 \pm 1.7$ & $17.8 \pm 2.1$ & $74.2 \pm 2.8$ \\
\hline $3 t$ & $\mathrm{Br}$ & $\mathrm{H}$ & $\mathrm{H}$ & $\mathrm{H}^{3}$ & $191.2 \pm 12$ & $134.8 \pm 9.7$ & $72.1 \pm 3.7$ & $69.6 \pm 4.1$ \\
\hline $3 \mathbf{u}$ & $\mathrm{Br}$ & $\mathrm{H}$ & $\mathrm{CH}_{3}$ & $\mathrm{H}$ & $76.9 \pm 3.7$ & $65.9 \pm 4.1$ & $91.2 \pm 7.1$ & $227.1 \pm 12.1$ \\
\hline $3 \mathbf{v}$ & $\mathrm{Br}$ & $\mathrm{H}$ & $\mathrm{H}^{3}$ & $\mathrm{OCH}_{3}$ & $63.4 \pm 5.4$ & $66.6 \pm 3.4$ & $59.6 \pm 3.9$ & $75.4 \pm 3.3$ \\
\hline $3 w$ & - & $\mathrm{H}$ & $\mathrm{H}$ & $\mathrm{H}^{3}$ & $54.9 \pm 3.6$ & $68.9 \pm 3.1$ & $92.7 \pm 3.8$ & $98.5 \pm 6.7$ \\
\hline $3 x$ & - & $\mathrm{H}$ & $\mathrm{CH}_{3}$ & $\mathrm{H}$ & $81.2 \pm 4.9$ & $64.7 \pm 2.4$ & $47.6 \pm 1.9$ & $89.3 \pm 5.8$ \\
\hline $3 y$ & - & $\mathrm{H}$ & $\mathrm{H}^{3}$ & $\mathrm{H}$ & $45.9 \pm 2.7$ & $183.7 \pm 12.9$ & $62.3 \pm 2.5$ & $128.3 \pm 8.7$ \\
\hline $3 z$ & - & $\mathrm{H}$ & $\mathrm{CH}_{3}$ & $\mathrm{H}$ & $125.6 \pm 8.9$ & $95.7 \pm 6.4$ & $42.1 \pm 2.8$ & $74.2 \pm 4.7$ \\
\hline Doxorubicin & & & & & $3.04 \pm 1.1$ & $2.51 \pm 0.9$ & $3.73 \pm 1.3$ & $5.05 \pm 1.7$ \\
\hline
\end{tabular}

${ }^{\star} \mathrm{IC}_{50}(\mu \mathrm{M})$ Inhibitory concentration; $\mathbf{3 w}, \mathbf{3 x}$ are linear and $\mathbf{3 y}, \mathbf{3 z}$ are the angular compounds.

Table 2. Anti-proliferative activity of pyrazolecarboxylates

\begin{tabular}{|c|c|c|c|c|c|c|c|c|c|}
\hline Compounds & $\mathbf{R}$ & $\mathbf{R}^{1}$ & $\mathbf{R}^{2}$ & $\mathbf{R}^{3}$ & $\mathbf{R}^{4}$ & A549 & HeLa & DU-145 & MDAMB 231 \\
\hline $5 \mathbf{a}$ & $\mathrm{H}$ & $\mathrm{H}$ & $\mathrm{H}$ & $\mathrm{H}$ & $\mathrm{CH}_{3}$ & $311 \pm 6.7$ & $296 \pm 5.7$ & $112 \pm 5.2$ & $130 \pm 3.8$ \\
\hline $5 \mathbf{b}$ & $\mathrm{H}$ & $\mathrm{H}$ & $\mathrm{CH}_{3}$ & $\mathrm{H}$ & $\mathrm{CH}_{3}^{3}$ & $070 \pm 3.5$ & $164 \pm 4.9$ & $087 \pm 4.3$ & $057 \pm 4.5$ \\
\hline $5 c$ & $\mathrm{H}$ & $\mathrm{H}$ & $\mathrm{H}^{3}$ & $\mathrm{OCH}_{3}$ & $\mathrm{CH}_{3}^{3}$ & $200>$ & $211 \pm 3.9$ & $061 \pm 3.7$ & $128 \pm 2.5$ \\
\hline $5 d$ & $\mathrm{H}$ & $\mathrm{H}$ & $\mathrm{F}$ & $\mathrm{H}^{3}$ & $\mathrm{CH}_{3}^{3}$ & $024 \pm 3.8$ & $233 \pm 4.1$ & $054 \pm 2.5$ & $080 \pm 3.2$ \\
\hline $5 e$ & $\mathrm{H}$ & $\mathrm{H}$ & $\mathrm{H}$ & $\mathrm{Br}$ & $\mathrm{CH}_{3}^{3}$ & $255 \pm 5.4$ & $194 \pm 3.9$ & $148 \pm 3.6$ & $200>$ \\
\hline $5 f$ & $\mathrm{H}$ & $\mathrm{Cl}$ & $\mathrm{H}$ & $\mathrm{Cl}$ & $\mathrm{CH}_{3}^{3}$ & $108 \pm 4.5$ & $139 \pm 4.6$ & $149 \pm 3.5$ & $200>$ \\
\hline $5 g$ & $\mathrm{CH}_{3}$ & $\mathrm{H}$ & $\mathrm{H}$ & $\mathrm{H}$ & $\mathrm{CH}_{3}^{3}$ & $045 \pm 4.9$ & $013 \pm 2.6$ & $200>$ & $070 \pm 4.6$ \\
\hline $5 \mathrm{~h}$ & $\mathrm{CH}_{3}^{3}$ & $\mathrm{H}$ & $\mathrm{CH}_{3}$ & $\mathrm{H}$ & $\mathrm{CH}_{3}^{3}$ & $051 \pm 3.4$ & $235 \pm 6.9$ & $019 \pm 2.1$ & $131 \pm 4.9$ \\
\hline $5 \mathbf{i}$ & $\mathrm{CH}_{3}^{3}$ & $\mathrm{H}$ & $\mathrm{H}^{3}$ & $\mathrm{OCH}_{3}$ & $\mathrm{CH}_{3}^{3}$ & $047 \pm 3.2$ & $081 \pm 5.6$ & $200>$ & $098 \pm 4.5$ \\
\hline $5 \mathbf{j}$ & $\mathrm{CH}_{3}^{3}$ & $\mathrm{H}$ & $\mathrm{F}$ & $\mathrm{H}^{3}$ & $\mathrm{CH}_{3}^{3}$ & $165 \pm 5.2$ & $330 \pm 6.8$ & $088 \pm 2.4$ & $128 \pm 4.9$ \\
\hline $5 \mathbf{k}$ & $\mathrm{CH}_{3}^{3}$ & $\mathrm{H}$ & $\mathrm{H}$ & $\mathrm{Br}$ & $\mathrm{CH}_{3}^{3}$ & $083 \pm 1.5$ & $072 \pm 2.9$ & $200>$ & $119 \pm 4.6$ \\
\hline 51 & $\mathrm{Cl}^{3}$ & $\mathrm{H}$ & $\mathrm{H}$ & $\mathrm{H}$ & $\mathrm{CH}_{3}^{3}$ & $056 \pm 3.7$ & $282 \pm 5.8$ & $123 \pm 4.2$ & $113 \pm 3.8$ \\
\hline $5 \mathrm{~m}$ & $\mathrm{Cl}$ & $\mathrm{H}$ & $\mathrm{CH}_{3}$ & $\mathrm{H}$ & $\mathrm{CH}_{3}^{3}$ & $119 \pm 5.7$ & $200>$ & $024 \pm 1.4$ & $078 \pm 3.4$ \\
\hline $5 n$ & $\mathrm{Cl}$ & $\mathrm{H}$ & $\mathrm{H}^{3}$ & $\mathrm{OCH}_{3}$ & $\mathrm{CH}_{3}^{3}$ & $085 \pm 6.4$ & $228 \pm 7.7$ & $065 \pm 4.2$ & $094 \pm 4.1$ \\
\hline 50 & $\mathrm{Br}$ & $\mathrm{H}$ & $\mathrm{H}$ & $\mathrm{H}^{3}$ & $\mathrm{CH}_{3}^{3}$ & $055 \pm 3.4$ & $213 \pm 7.6$ & $100>$ & $065 \pm 6.1$ \\
\hline $5 p$ & $\mathrm{Br}$ & $\mathrm{H}$ & $\mathrm{CH}_{3}$ & $\mathrm{H}$ & $\mathrm{CH}_{3}^{3}$ & $111 \pm 6.1$ & $194 \pm 5.1$ & $005 \pm 1.0$ & $019 \pm 2.1$ \\
\hline $5 q$ & $\mathrm{Br}$ & $\mathrm{H}$ & $\mathrm{H}^{3}$ & $\mathrm{OCH}_{3}$ & $\mathrm{CH}_{3}^{3}$ & $183 \pm 8.7$ & $073 \pm .2$ & $200>$ & $011 \pm 2.1$ \\
\hline $5 r$ & $\mathrm{H}$ & $\mathrm{H}$ & $\mathrm{H}$ & $\mathrm{H}^{3}$ & $\mathrm{C}_{2} \mathrm{H}_{5}^{3}$ & $066 \pm 4.0$ & $161 \pm 4.8$ & $084 \pm 2.4$ & $200>$ \\
\hline $5 s$ & - & $\mathrm{H}$ & $\mathrm{H}$ & $\mathrm{H}$ & $\mathrm{CH}_{3}^{2}$ & $025 \pm 2.5$ & $200>$ & $200>$ & $094 \pm 3.9$ \\
\hline $5 t$ & - & $\mathrm{H}$ & $\mathrm{CH}_{3}$ & $\mathrm{H}$ & $\mathrm{CH}_{3}^{3}$ & $068 \pm 3.7$ & $200>$ & $200>$ & $200>$ \\
\hline $5 \mathbf{u}$ & - & $\mathrm{H}$ & $\mathrm{H}^{3}$ & $\mathrm{H}$ & $\mathrm{C}_{2} \mathrm{H}_{5}^{3}$ & $90 \pm 5.10$ & $027 \pm 2.2$ & $067 \pm 5.1$ & $200>$ \\
\hline $5 v$ & - & $\mathrm{H}$ & $\mathrm{H}$ & $\mathrm{H}$ & $\mathrm{CH}_{3}^{5}$ & $200>$ & $200>$ & $200>$ & $049 \pm 2.8$ \\
\hline $5 w$ & - & $\mathrm{H}$ & $\mathrm{CH}_{3}$ & $\mathrm{H}$ & $\mathrm{CH}_{3}^{3}$ & $115 \pm 4.1$ & $005 \pm 1.5$ & $015 \pm 2.1$ & $075 \pm 4.4$ \\
\hline $5 x$ & - & $\mathrm{H}$ & $\mathrm{H}^{3}$ & $\mathrm{H}$ & $\mathrm{C}_{2} \mathrm{H}_{5}^{3}$ & $079 \pm 4.8$ & $033 \pm 2.9$ & $200>$ & $076 \pm 4.5$ \\
\hline Doxorubicin & & & & & & $3.04 \pm 1.1$ & $3.73 \pm 1.3$ & $2.51 \pm 0.9$ & $5.05 \pm 1.7$ \\
\hline
\end{tabular}

\footnotetext{
${ }^{\star} \mathrm{IC}_{50}(\mu \mathrm{M})$ Inhibitory concentration; $\mathbf{5 s}-\mathbf{u}$ are the linear and $\mathbf{5 v}-\mathbf{x}$ are the angular compounds.
} 


\section{3. Anti-proliferative Activity of Pyrazolylmethanones 6a-u}

The anti-proliferative activity of pyrazolylmethanones $\mathbf{6 a}-\mathbf{u}$ and their $\mathrm{IC}_{50}$ values along with the standard drug are presented in Table 3 . The compounds $\mathbf{6 a}-\mathbf{h}$ displayed activity in the range of $\mathrm{IC}_{50} 10.8-164.9 \mu \mathrm{M}$ in all the tested cell lines. The fluoro substituted pyrazole $\mathbf{6 e}\left(\mathrm{IC}_{50}\right.$ $10.8 \mu \mathrm{M})$ has shown potent activity on HeLa cell line and promising activity on $\mathrm{A} 549\left(\mathrm{IC}_{50} 15.6 \mu \mathrm{M}\right)$ when compared to the corresponding methyl $\mathbf{6 b}$, methoxy $\mathbf{6 c}$, chloro $\mathbf{6 f}$ and bromo $\mathbf{6 h}$ derivatives. It is interesting to note that the fluoro substituent on the meta position $6 \mathbf{e}$ displayed activity when compared to ortho $\mathbf{6 d}$ and para $\mathbf{6 g}$ analogues. The compound having a methyl substituent on the phenyl ring and a methoxy group on the pyrazole phenyl moiety $6 \mathbf{j}\left(\mathrm{IC}_{50} 7.9 \mu \mathrm{M}\right)$ has shown potent activity on HeLa cell line and promising activity on DU145, A549 ( IC $_{50}$ $16.1,19.9 \mu \mathrm{M})$, respectively when compared to methyl $\mathbf{6 i}$ and halogen derivatives $\mathbf{6 k - 6 n}$.

Overall in the present series of compounds the hydrazone derivative $3 \mathrm{~s}$ displayed promising activity on three cell lines (A549, $\mathrm{IC}_{50}$ 19.7; HeLa, $\mathrm{IC}_{50}$ 14.0; DU145, $\mathrm{IC}_{50}$ $17.8 \mu \mathrm{M})$. Pyrazole carboxylates $\mathbf{5 p}$ and $\mathbf{5 w}\left(\mathrm{IC}_{50} 5.0 \mu \mathrm{M}\right)$ displayed potent activity on DU145, HeLa and promising activity on MDAMB 231 $\left(\mathrm{IC}_{50} 19.0 \mu \mathrm{M}\right)$ and DU145 $\left(\mathrm{IC}_{50}\right.$ $15.0 \mu \mathrm{M})$. The compound $\mathbf{5 q}\left(\mathrm{IC}_{50} 11.0 \mu \mathrm{M}\right)$ displayed potent activity selectively on MDAMB 231 . Pyrazolylmethanone $6 \mathbf{e}\left(\mathrm{IC}_{50} 10.8,15.6 \mu \mathrm{M}\right)$ displayed potent activity on
HeLa and promising activity on A549. Compound $\mathbf{6 j}$ (IC $\mathrm{IC}_{50}$ 7.9, 16.1, $19.9 \mu \mathrm{M})$ displayed potent activity on HeLa, promising activity on DU145 and A549, respectively.

\section{Experimental}

\section{1. Chemistry}

${ }^{1} \mathrm{H}$ NMR and ${ }^{13} \mathrm{C}$ NMR spectra were recorded on an Avance $300 \mathrm{MHz}$ spectrometer in $\mathrm{CDCl}_{3}$ using TMS as internal standard. FT-IR spectra were recorded on a Nicollet 740 FT-IR spectrometer. Mass spectra were obtained on Agilent ESI-MS instrument. Melting points were determined in open glass capillary tubes on a Mettler FP 51 melting point apparatus and are uncorrected. All the reactions were monitored by thin layer chromatography (TLC) on pre-coated silica gel (60 $\mathrm{F}_{254}$ mesh); spots were visualized under UV light. Merck silica gel (60-120; 100-200 mesh) was used for chromatography. All the reactions were carried out using reagent-grade solvents. The reagents were purchased from Sigma-Aldrich and local suppliers (Sd fine \& AVRA chemicals Pvt. Ltd, Hyderabad, India).

\section{2. General Procedure for the Preparation of Hydrazones 3a-z}

The warmed solution of phenylhydrazine hydrochloride $2 \mathbf{a}(0.172 \mathrm{~g}, 1.2 \mathrm{mmol})$ and acetic acid $(0.5 \mathrm{~mL}$ in $1 \mathrm{~mL}$

Table 3. Anti-proliferative activity of pyrazolylmethanones

\begin{tabular}{|c|c|c|c|c|c|c|c|c|}
\hline Compounds & $\mathbf{R}$ & $\mathbf{R}^{1}$ & $\mathbf{R}^{2}$ & $\mathbf{R}^{3}$ & A549 & HeLa & DU-145 & MDAMB 231 \\
\hline $6 a$ & $\mathrm{H}$ & $\mathrm{H}$ & $\mathrm{H}$ & $\mathrm{H}$ & $44.4 \pm 2.4$ & $164.9 \pm 9.5$ & $45.1 \pm 2.7$ & $52.1 \pm 3.4$ \\
\hline $6 b$ & $\mathrm{H}$ & $\mathrm{H}$ & $\mathrm{CH}_{3}$ & $\mathrm{H}$ & $126.7 \pm 6$ & $86.8 \pm 2.8$ & $83.3 \pm 3.5$ & $93.5 \pm 4.8$ \\
\hline $6 c$ & $\mathrm{H}$ & $\mathrm{H}$ & $\mathrm{H}^{3}$ & $\mathrm{OCH}_{3}$ & $143.2 \pm 9$ & $85.3 \pm 3.1$ & $46.7 \pm 6.1$ & $119.3 \pm 7.7$ \\
\hline 6d & $\mathrm{H}$ & $\mathrm{F}$ & $\mathrm{H}$ & $\mathrm{H}^{3}$ & $62.3 \pm 2.5$ & $51.1 \pm 2.9$ & $87.2 \pm 5.8$ & $98.7 \pm 3.9$ \\
\hline $6 e$ & $\mathrm{H}$ & $\mathrm{H}$ & $\mathrm{F}$ & $\mathrm{H}$ & $15.6 \pm 2.7$ & $10.8 \pm 1.6$ & $26.1 \pm 2.4$ & $45.8 \pm 3.1$ \\
\hline $6 f$ & $\mathrm{H}$ & $\mathrm{H}$ & $\mathrm{Cl}$ & $\mathrm{H}$ & $98.5 \pm 8.1$ & $83.8 \pm 4.1$ & $60 \pm 3.8$ & $86.6 \pm 5.6$ \\
\hline $6 g$ & $\mathrm{H}$ & $\mathrm{H}$ & $\mathrm{H}$ & $\mathrm{F}$ & $82.1 \pm 4.6$ & $164.9 \pm 5.8$ & $51.2 \pm 5.2$ & $91.5 \pm 4.9$ \\
\hline $6 \mathrm{~h}$ & $\mathrm{H}$ & $\mathrm{H}$ & $\mathrm{H}$ & $\mathrm{Br}$ & $42.5 \pm 3.7$ & $56.9 \pm 2.7$ & $63.7 \pm 4.9$ & $65.2 \pm 3.5$ \\
\hline $6 i$ & $\mathrm{CH}_{3}$ & $\mathrm{H}$ & $\mathrm{CH}_{3}$ & $\mathrm{H}$ & $68.5 \pm 3.1$ & $45.5 \pm 3.5$ & $47.2 \pm 2.9$ & $78.6 \pm 5.1$ \\
\hline $6 \mathbf{j}$ & $\mathrm{CH}_{3}^{3}$ & $\mathrm{H}$ & $\mathrm{H}^{3}$ & $\mathrm{OCH}_{3}$ & $19.9 \pm 1.9$ & $7.9 \pm 1.1$ & $16.1 \pm 2.5$ & $35.2 \pm 2.8$ \\
\hline $6 \mathrm{k}$ & $\mathrm{CH}_{3}$ & $\mathrm{~F}$ & $\mathrm{H}$ & $\mathrm{H}$ & $70.8 \pm 4.3$ & $73.7 \pm 3.1$ & $245.9 \pm 9.7$ & $215.1 \pm 12.4$ \\
\hline 61 & $\mathrm{CH}_{3}^{3}$ & $\mathrm{H}$ & $\mathrm{F}$ & $\mathrm{H}$ & $82.2 \pm 3.5$ & $58.2 \pm 3.7$ & $54.4 \pm 4.1$ & $119.4 \pm 8.9$ \\
\hline $6 m$ & $\mathrm{CH}_{3}^{3}$ & $\mathrm{H}$ & $\mathrm{H}$ & $\mathrm{F}$ & $59.9 \pm 2.9$ & $49.3 \pm 2.1$ & $66.7 \pm 1.9$ & $185.4 \pm 9.1$ \\
\hline $6 n$ & $\mathrm{CH}_{3}$ & $\mathrm{H}$ & $\mathrm{H}$ & $\mathrm{Br}$ & $164.9 \pm 7$ & $67.7 \pm 3.9$ & $54.3 \pm 2.3$ & $85.2 \pm 3.7$ \\
\hline 60 & $\mathrm{Cl}^{3}$ & $\mathrm{H}$ & $\mathrm{H}$ & $\mathrm{H}$ & $82.7 \pm 6.4$ & $50.2 \pm 3.1$ & $119.5 \pm 6.7$ & $175.2 \pm 9.4$ \\
\hline $6 p$ & $\mathrm{Cl}$ & $\mathrm{H}$ & $\mathrm{CH}_{3}$ & $\mathrm{H}$ & $52.9 \pm 2.9$ & $71.3 \pm 2.4$ & $55.5 \pm 3.1$ & $76.5 \pm 1.8$ \\
\hline $6 q$ & $\mathrm{Cl}$ & $\mathrm{H}$ & $\mathrm{H}^{3}$ & $\mathrm{OCH}_{3}$ & $98.3 \pm 8.1$ & $51.4 \pm 2.9$ & $116.1 \pm 5.8$ & $83.5 \pm 2.7$ \\
\hline $6 r$ & $\mathrm{Br}$ & $\mathrm{H}$ & $\mathrm{CH}_{3}$ & $\mathrm{H}$ & $220.2 \pm 11$ & $170.3 \pm 9.8$ & $64.5 \pm 6.4$ & $128.3 \pm 6.7$ \\
\hline $6 s$ & $\mathrm{Br}$ & $\mathrm{H}$ & $\mathrm{H}^{3}$ & $\mathrm{OCH}_{3}$ & $61.3 \pm 3.8$ & $51.4 \pm 1.9$ & $66.1 \pm 2.9$ & $75.8 \pm 4.1$ \\
\hline $6 t$ & - & $\mathrm{H}$ & $\mathrm{H}$ & $\mathrm{H}^{3}$ & $45.6 \pm 5.4$ & $164.9 \pm 11.2$ & $62.4 \pm 4.5$ & $86.5 \pm 1.6$ \\
\hline $6 u$ & - & $\mathrm{H}$ & $\mathrm{CH}_{3}$ & $\mathrm{H}$ & $125.9 \pm 9$ & $50.9 \pm 3.7$ & $82.7 \pm 2.3$ & $75.6 \pm 2.4$ \\
\hline Doxorubicin & & & & & $3.04 \pm 1.1$ & $2.51 \pm 0.9$ & $3.73 \pm 1.3$ & $5.05 \pm 1.7$ \\
\hline
\end{tabular}

${ }^{\star} \mathrm{IC}_{50}(\mu \mathrm{M})$ Inhibitory concentration; $\mathbf{6 t}-\mathbf{u}$ are the linear compounds. 
$\mathrm{H}_{2} \mathrm{O}$ ) was added to a stirred solution of 3-formylchromone $(0.174 \mathrm{~g}, 1 \mathrm{mmol})$ in methanol $(2 \mathrm{~mL})$ at room temperature. The reaction mixture was heated to $60{ }^{\circ} \mathrm{C}$ for $30 \mathrm{~min}$ and then cooled to room temperature. The solid separated was filtered, washed with ice-cold water $(5 \mathrm{~mL})$ and then recrystallized from hot methanol providing the corresponding hydrazone 3a. Similarly, the other hydrazones $\mathbf{3 b}-\mathbf{z}$ were prepared from the corresponding 3-formylchromones 1a-f and phenylhydrazine hydrochlorides 2a-i under optimized reaction conditions.

(E)-3-((2-Phenylhydrazono)methyl)-4H-chromen-4-one (3a)

Yellow solid. Yield $88 \%$. M.p. $212-213{ }^{\circ} \mathrm{C}$. FT-IR (KBr): $v 3265,1618,1526,1258,1171 \mathrm{~cm}^{-1} .{ }^{1} \mathrm{H}$ NMR $(300$ $\left.\mathrm{MHz}, \mathrm{CDCl}_{3}+\mathrm{DMSO}-d_{6}\right): \delta 8.66(\mathrm{~s}, 1 \mathrm{H}$, imine), 8.14 (dd, $\left.1 \mathrm{H}, J_{1}=6.2 \mathrm{~Hz}, J_{2}=7.8 \mathrm{~Hz}\right), 7.97(\mathrm{~s}, 1 \mathrm{H}, \mathrm{Ar}-\mathrm{H}), 7.77(\mathrm{t}, 1 \mathrm{H}$, $J=6.2 \mathrm{~Hz}, \mathrm{Ar}-\mathrm{H}), 7.60(\mathrm{~d}, 1 \mathrm{H}, J=8.5 \mathrm{~Hz}, \mathrm{Ar}-\mathrm{H}), 7.47(\mathrm{t}$, $1 \mathrm{H}, J=8.8 \mathrm{~Hz}, \mathrm{Ar}-\mathrm{H}), 7.17(\mathrm{t}, 2 \mathrm{H}, J=7.0 \mathrm{~Hz}, \mathrm{Ar}-\mathrm{H}), 7.04$ $(\mathrm{d}, 2 \mathrm{H}, J=7.0 \mathrm{~Hz}, \mathrm{Ar}-\mathrm{H}), 6.72(\mathrm{t}, 1 \mathrm{H}, J=7.8 \mathrm{~Hz}, \mathrm{Ar}-\mathrm{H}) .{ }^{13} \mathrm{C}$ NMR $\left(75 \mathrm{MHz}, \mathrm{CDCl}_{3}+\mathrm{DMSO}-d_{6}\right): \delta 173.6,154.9,152.1$, 144.5, 142.0, 133.7, 132.1, 128.7, 128.4, 127.1, 123.7, 122.3, 118.9, 118.4, 111.7. ESI-MS: $m / z[\mathrm{M}+\mathrm{H}]^{+} 265$.

(E)-3-((2-m-Tolylhydrazono) methyl)-4H-chromen-4one (3b)

Yellow solid. Yield $76 \%$. M.p. $231-233{ }^{\circ} \mathrm{C}$. FT-IR (KBr): $v 2977,1622,1571,1491,1206,1130,1094,872,748$ $\mathrm{cm}^{-1} .{ }^{1} \mathrm{H}$ NMR $\left(300 \mathrm{MHz}, \mathrm{CDCl}_{3}+\mathrm{DMSO}-d_{6}\right): \delta 8.46(\mathrm{~s}$, $1 \mathrm{H}$, imine), 7.90 (s, 1H, Ar-H), $7.86(\mathrm{~s}, 1 \mathrm{H}, \mathrm{Ar}-\mathrm{H}), 7.43$ (d, $1 \mathrm{H}, J=8.8 \mathrm{~Hz}, \mathrm{Ar}-\mathrm{H}), 7.34(\mathrm{~d}, 1 \mathrm{H}, J=8.8 \mathrm{~Hz}, \mathrm{Ar}-\mathrm{H}), 7.07$ $(\mathrm{t}, 2 \mathrm{H}, J=8.8,6.8 \mathrm{~Hz}, \mathrm{Ar}-\mathrm{H}), 6.95(\mathrm{~d}, 2 \mathrm{H}, J=7.8 \mathrm{~Hz}$, Ar-H), $6.63\left(\mathrm{t}, 1 \mathrm{H}, J=7.8 \mathrm{~Hz}\right.$, Ar-H). ESI-MS: $m / z[\mathrm{M}+\mathrm{H}]^{+}$ 278.

(E)-3-((2-(4-Methoxyphenyl)hydrazono)methyl)-4Hchromen-4-one (3c)

Yellow solid. Yield $89 \%$. M.p. $237-239{ }^{\circ} \mathrm{C}$. FT-IR (KBr): $v 3271,2901,1621,1570,1464,1228,1042,827,791$ $\mathrm{cm}^{-1} .{ }^{1} \mathrm{H}$ NMR $\left(300 \mathrm{MHz}, \mathrm{CDCl}_{3}+\mathrm{DMSO}-d_{6}\right): \delta 8.66(\mathrm{~s}$, $1 \mathrm{H}$, imine), $8.13\left(\mathrm{dd}, 1 \mathrm{H}, J_{1}=6.8 \mathrm{~Hz}, J_{2}=8.8 \mathrm{~Hz}, \mathrm{Ar}-\mathrm{H}\right)$, $7.92(\mathrm{~s}, 1 \mathrm{H}, J=7.8 \mathrm{~Hz}, \mathrm{Ar}-\mathrm{H}), 7.82-7.76(\mathrm{~m}, 1 \mathrm{H}, \mathrm{Ar}-\mathrm{H})$, 7.66-7.60 (m, 1H, Ar-H), 7.52-7.46 (m, 1H, Ar-H), 7.02$6.98(\mathrm{~m}, 2 \mathrm{H}, \mathrm{Ar}-\mathrm{H}), 6.82-6.76(\mathrm{~m}, 2 \mathrm{H}, \mathrm{Ar}-\mathrm{H}), 3.72(\mathrm{~s}, 3 \mathrm{H}$, $\left.\mathrm{OCH}_{3}\right) \cdot{ }^{13} \mathrm{C}$ NMR $\left(75 \mathrm{MHz}, \mathrm{CDCl}_{3}+\mathrm{DMSO}-d_{6}\right): \delta 163.5$, $150.3,145.4,131.9,131.1,128.4,123.9,119.2,119.1,117.2$, 115.3, 52.3. ESI-MS: $m / z 295[\mathrm{M}+\mathrm{H}]^{+}$.

(E)-3-((2-(2-Fluorophenyl)hydrazono) methyl)-4Hchromen-4-one (3d)

Yellow solid. Yield $71 \%$. M.p. $232-234{ }^{\circ} \mathrm{C} .{ }^{1} \mathrm{H}$ NMR $\left(300 \mathrm{MHz}, \mathrm{CDCl}_{3}+\mathrm{DMSO}-d_{6}\right): \delta 8.60(\mathrm{~s}, 1 \mathrm{H}$, imine), 8.23 (s, $1 \mathrm{H}, \mathrm{Ar}-\mathrm{H}), 8.16(\mathrm{~d}, 1 \mathrm{H}, J=7.9 \mathrm{~Hz}, \mathrm{Ar}-\mathrm{H}), 7.73(\mathrm{t}, 1 \mathrm{H}, J$ $=6.9 \mathrm{~Hz}, \mathrm{Ar}-\mathrm{H}), 7.50-7.42(\mathrm{~m}, 2 \mathrm{H}, \mathrm{Ar}-\mathrm{H}), 7.04-6.94(\mathrm{~m}$, $2 \mathrm{H}, \mathrm{Ar}-\mathrm{H}), 6.70(\mathrm{t}, 1 \mathrm{H}, J=6.9 \mathrm{~Hz}, \mathrm{Ar}-\mathrm{H}) .{ }^{13} \mathrm{C}$ NMR $(75$ $\left.\mathrm{MHz}, \mathrm{CDCl}_{3}+\mathrm{DMSO}-d_{6}\right): \delta 175.1,155.9,153.0,150.8$,
$142.5,134.5,131.2,130.6,125.4,123.5,118.8,114.3$. ESIMS: $m / z[\mathrm{M}+\mathrm{H}]^{+} 283$.

(E)-3-((2-(3-Fluorophenyl)hydrazono)methyl)-4Hchromen-4-one (3e)

Yellow solid. Yield $73 \%$. M.p. $249-251{ }^{\circ} \mathrm{C}$. FT-IR $(\mathrm{KBr}): v 3265,2793,1623,1484,1171,816,779 \mathrm{~cm}^{-1} .{ }^{1} \mathrm{H}$ NMR (300 MHz, CDCl 3 DMSO- $\left.d_{6}\right): \delta 8.78(\mathrm{~s}, 1 \mathrm{H}$, imine), $8.02(\mathrm{~s}, 1 \mathrm{H}), 7.98(\mathrm{~s}, 1 \mathrm{H}, \mathrm{Ar}-\mathrm{H}), 7.60(\mathrm{~d}, 1 \mathrm{H}, J=8.8 \mathrm{~Hz}$, Ar-H), $7.54(\mathrm{~d}, 1 \mathrm{H}, J=8.8 \mathrm{~Hz}, \mathrm{Ar}-\mathrm{H}), 6.98$ (s, 2H, Ar-H), $6.74(\mathrm{~s}, 1 \mathrm{H}, \mathrm{Ar}-\mathrm{H})$.

(E)-3-((2-(3-Chlorophenyl)hydrazono) methyl)-4Hchromen-4-one (3f)

Yellow solid. Yield 69\%. M.p. $254-256{ }^{\circ} \mathrm{C} .{ }^{1} \mathrm{H}$ NMR $\left(300 \mathrm{MHz}, \mathrm{CDCl}_{3}+\mathrm{DMSO}-d_{6}\right): \delta 8.67(\mathrm{~s}, 1 \mathrm{H}$, imine), 8.21 $(\mathrm{d}, 1 \mathrm{H}, J=7.9 \mathrm{~Hz}, \mathrm{Ar}-\mathrm{H}), 8.04(\mathrm{~s}, 1 \mathrm{H}, \mathrm{Ar}-\mathrm{H}), 7.93(\mathrm{~d}, 1 \mathrm{H}, J$ $=1.2 \mathrm{~Hz}, \mathrm{Ar}-\mathrm{H}), 7.76(\mathrm{~d}, 1 \mathrm{H}, J=7.9 \mathrm{~Hz}, \mathrm{Ar}-\mathrm{H}), 7.65-7.43$ $(\mathrm{m}, 2 \mathrm{H}, \mathrm{Ar}-\mathrm{H}), 7.11(\mathrm{~s}, 1 \mathrm{H}, \mathrm{Ar}-\mathrm{H}), 6.96(\mathrm{~d}, 1 \mathrm{H}, J=8.6 \mathrm{~Hz}$, Ar-H), $7.70(\mathrm{~d}, 1 \mathrm{H}, J=7.2 \mathrm{~Hz}, \mathrm{Ar}-\mathrm{H}) .{ }^{13} \mathrm{C}$ NMR $(75 \mathrm{MHz}$, $\left.\mathrm{CDCl}_{3}+\mathrm{DMSO}-d_{6}\right): \delta 173.4,161.0,154.2,150.3,144.7$, $132.5,132.2$, 128.5, 127.6, 123.6, 121.8, 117.9, 116.6, 109.9, 108.9 .

(E)-3-((2-(4-Fluorophenyl)hydrazono) methyl)-4Hchromen-4-one (3g)

Yellow solid. Yield 73\%. M.p. $241-243{ }^{\circ} \mathrm{C} .{ }^{1} \mathrm{H}$ NMR $\left(300 \mathrm{MHz}, \mathrm{CDCl}_{3}+\mathrm{DMSO}-d_{6}\right): \delta 8.80(\mathrm{~s}, 1 \mathrm{H}$, imine), 8.12 (dd, $\left.1 \mathrm{H}, J_{1}=7.9 \mathrm{~Hz}, J_{2}=1.5 \mathrm{~Hz}, \mathrm{Ar}-\mathrm{H}\right), 7.96(\mathrm{~s}, 1 \mathrm{H}, \mathrm{Ar}-\mathrm{H})$, $7.82\left(\mathrm{dt}, 1 \mathrm{H}, J_{1}=8.6 \mathrm{~Hz}, J_{2}=7.6 \mathrm{~Hz}, J_{3}=1.8 \mathrm{~Hz}, \mathrm{Ar}-\mathrm{H}\right), 7.69$ $(\mathrm{d}, 1 \mathrm{H}, J=8.1 \mathrm{~Hz}, \mathrm{Ar}-\mathrm{H}), 7.52(\mathrm{t}, 2 \mathrm{H}, J=7.1 \mathrm{~Hz}, \mathrm{Ar}-\mathrm{H}), 7.06$ $(\mathrm{d}, 3 \mathrm{H}, J=6.6 \mathrm{~Hz}, \mathrm{Ar}-\mathrm{H}) .{ }^{13} \mathrm{C} \mathrm{NMR}\left(75 \mathrm{MHz}, \mathrm{CDCl}_{3}+\right.$ DMSO- $d_{6}$ ): $\delta 190.3,175.2,158.7,152.5,142.7,134.5,132.1$, $130.9,128.1,125.4,123.4,119.5,118.8,117.5,115.9$.

(E)-3-((2-(4-Bromophenyl)hydrazono) methyl)-4Hchromen-4-one (3h)

Pale yellow solid. Yield 77\%. M.p. $226-228^{\circ} \mathrm{C}$. FT-IR (KBr): v 3271, 2901, 1621, 1570, 1464, 1228, 1042, 827, 791 $\mathrm{cm}^{-1} .{ }^{1} \mathrm{H}$ NMR $\left(300 \mathrm{MHz}, \mathrm{CDCl}_{3}+\mathrm{DMSO}-d_{6}\right): \delta 8.81(\mathrm{~s}$, $1 \mathrm{H}$, imine), $8.11(\mathrm{~d}, 2 \mathrm{H}, J=7.8 \mathrm{~Hz}, \operatorname{Ar}-\mathrm{H}), 7.97(\mathrm{~s}, 1 \mathrm{H}$, Ar-H), $7.81(\mathrm{t}, 1 \mathrm{H}, J=8.4 \mathrm{~Hz}, \mathrm{Ar}-\mathrm{H}), 7.68(\mathrm{~d}, 1 \mathrm{H}, J=8.3$ $\mathrm{Hz}, \mathrm{Ar}-\mathrm{H}), 7.35$ (d, 2H, $J=8.6 \mathrm{~Hz}, \mathrm{Ar}-\mathrm{H}), 7.01(\mathrm{~d}, 2 \mathrm{H}, J=$ $8.6 \mathrm{~Hz}, \mathrm{Ar}-\mathrm{H}) .{ }^{13} \mathrm{C}$ NMR $\left(75 \mathrm{MHz}, \mathrm{CDCl}_{3}+\mathrm{DMSO}-d_{6}\right): \delta$ $173.2,153.9,150.2,142.4,132.2,129.7,127.0,123.6,123.4$, $121.5,117.7,116.6,112.1,108.0$.

(E)-3-((2-(2,4-Dichlorophenyl)hydrazono)methyl)-4Hchromen-4-one (3i)

Yellow solid. Yield $64 \%$. M.p. $225-227{ }^{\circ} \mathrm{C}$. FT-IR (KBr): $v 3265,2793,1623,1484,1171 \mathrm{~cm}^{-1} .{ }^{1} \mathrm{H}$ NMR $(300$ $\left.\mathrm{MHz}, \mathrm{CDCl}_{3}+\mathrm{DMSO}-d_{6}\right): \delta 8.76(\mathrm{~s}, 1 \mathrm{H}$, imine), $8.40(\mathrm{~s}$, $1 \mathrm{H}), 8.14\left(\mathrm{t}, 1 \mathrm{H}, J_{1}=6.8 \mathrm{~Hz}, J_{2}=8.8 \mathrm{~Hz}, \operatorname{Ar}-\mathrm{H}\right), 7.80(\mathrm{dd}$, $\left.2 \mathrm{H}, J_{1}=7.9 \mathrm{~Hz}, J_{2}=7.1 \mathrm{~Hz}, \mathrm{Ar}-\mathrm{H}\right), 7.66-7.46(\mathrm{~m}, 3 \mathrm{H}$, Ar-H), $6.20\left(\mathrm{~d}, 1 \mathrm{H}, J=7.8 \mathrm{~Hz}\right.$, Ar-H). ESI-MS: $m / z[\mathrm{M}+\mathrm{H}]^{+}$ 333. 
(E)-6-Methyl-3-((2-phenylhydrazono) methyl)-4Hchromen-4-one (3j)

Yellow solid. Yield $72 \%$. M.p. $203-205{ }^{\circ} \mathrm{C}$. FT-IR $(\mathrm{KBr}): v$ 3265, 2977, 1622, 1571, 1491, 1206, 1130, 1094, $872,748 \mathrm{~cm}^{-1} .{ }^{1} \mathrm{H}$ NMR $\left(300 \mathrm{MHz}, \mathrm{CDCl}_{3}+\mathrm{DMSO}-d_{6}\right): \delta$ $8.55(\mathrm{~s}, 1 \mathrm{H}$, imine), $8.03(\mathrm{~d}, 1 \mathrm{H}, J=8.8 \mathrm{~Hz}), 7.98(\mathrm{~s}, 1 \mathrm{H}$, Ar-H), 7.35 (s, 1H, Ar-H), 7.26 (d, $1 \mathrm{H}, J=8.8 \mathrm{~Hz}, \mathrm{Ar}-\mathrm{H})$, $7.17(\mathrm{t}, 2 \mathrm{H}, J=8.8 \mathrm{~Hz}, \mathrm{Ar}-\mathrm{H}), 7.04(\mathrm{~d}, 2 \mathrm{H}, J=7.8 \mathrm{~Hz}$, Ar-H), 6.73 (t, $1 \mathrm{H}, J=7.8 \mathrm{~Hz}, \mathrm{Ar}-\mathrm{H}) \cdot{ }^{13} \mathrm{C}$ NMR $(75 \mathrm{MHz}$, $\mathrm{CDCl}_{3}+$ DMSO- $\left.d_{6}\right): \delta 173.6,161.6,150.4,146.6,141.3$, $138.2,130.3,129.7,128.7,126.8,124.4,122.4,119.6,118.7$, 117.4, 111.4, 21.0. ESI-MS: $m / z[\mathrm{M}+\mathrm{H}]^{+} 279$.

(E)-6-Methyl-3-((2-m-tolylhydrazono) methyl)-4Hchromen-4-one (3k)

Yellow solid. Yield $71 \%$. M.p. $222-224{ }^{\circ} \mathrm{C}$. FT-IR (KBr): v 3276, 1640, $1608 \mathrm{~cm}^{-1} .{ }^{1} \mathrm{H}$ NMR $\left(300 \mathrm{MHz}, \mathrm{CDCl}_{3}\right.$ + DMSO- $\left.d_{6}\right): \delta 8.55$ (s, $1 \mathrm{H}$, imine), $7.96(\mathrm{~s}, 1 \mathrm{H}, \mathrm{Ar}-\mathrm{H}), 7.92$ (s, $1 \mathrm{H}, \operatorname{Ar}-\mathrm{H}), 7.52(\mathrm{~d}, 1 \mathrm{H}, J=7.0 \mathrm{~Hz}, \operatorname{Ar}-\mathrm{H}), 7.44(\mathrm{~d}, 1 \mathrm{H}, J$ $=8.0 \mathrm{~Hz}, \mathrm{Ar}-\mathrm{H}), 7.02(\mathrm{t}, 1 \mathrm{H}, J=8.0 \mathrm{~Hz}, \mathrm{Ar}-\mathrm{H}), 6.85(\mathrm{~s}, 1 \mathrm{H}$, Ar-H), $6.81(\mathrm{~d}, 1 \mathrm{H}, J=8.0 \mathrm{~Hz}, \mathrm{Ar}-\mathrm{H}), 6.52(\mathrm{~d}, 1 \mathrm{H}, J=7.0$ $\mathrm{Hz}, \mathrm{Ar}-\mathrm{H}) .{ }^{13} \mathrm{C}$ NMR $\left(75 \mathrm{MHz}, \mathrm{CDCl}_{3}+\mathrm{DMSO}_{-} d_{6}\right): \delta$ 174.6, 153.7, 151.7, 144.7, 137.9, 135.0, 134.9, 128.6, 127.5, 124.1, 122.6, 119.5, 119.1, 118.1, 112.2, 109.1, 21.0, 20.2. ESI-MS: $m / z[\mathrm{M}+\mathrm{H}]^{+} 293$.

(E)-3-((2-(4-Methoxyphenyl)hydrazono)methyl)-6methyl-4H-chromen-4-one (31)

Yellow solid. Yield 79\%. M.p. $246-248^{\circ} \mathrm{C}$. FT-IR (KBr): $v$ 3271, 2901, 1621, 1570, 1464, 1228, 1042, 827, $791 \mathrm{~cm}^{-1} .{ }^{1} \mathrm{H}$ NMR $\left(300 \mathrm{MHz}, \mathrm{CDCl}_{3}+\mathrm{DMSO}-d_{6}\right): \delta 8.57(\mathrm{~s}, 1 \mathrm{H}$, imine), $7.95(\mathrm{~d}, 1 \mathrm{H}, J=7.8 \mathrm{~Hz}, \mathrm{Ar}-\mathrm{H}), 7.54(\mathrm{~s}, 1 \mathrm{H}, \mathrm{Ar}-\mathrm{H}), 7.37(\mathrm{~s}, 1 \mathrm{H}$, Ar-H), 7.20 (s, 1H, Ar-H), 7.01 (d, $2 \mathrm{H}, J=8.6 \mathrm{~Hz}$, Ar-H), $6.78(\mathrm{~d}, 2 \mathrm{H}, J=8.6 \mathrm{~Hz}, \mathrm{Ar}-\mathrm{H}), 3.74\left(\mathrm{~s}, 3 \mathrm{H}, \mathrm{OCH}_{3}\right), 2.48(\mathrm{~s}$, $\left.3 \mathrm{H}, \mathrm{CH}_{3}\right) \cdot{ }^{13} \mathrm{C} \mathrm{NMR}\left(75 \mathrm{MHz}, \mathrm{CDCl}_{3}+\mathrm{DMSO}-d_{6}\right): \delta 173.0$, $152.1,150.8,149.4,137.2,124.8,122.5,121.1,117.8,116.3$, 112.5, 111.1, 53.3, 18.7. ESI-MS: $m / z[\mathrm{M}+\mathrm{H}]^{+} 309$.

(E)-3-((2-(2-Fluorophenyl)hydrazono)methyl)-6-methyl-4H-chromen-4-one (3m)

Yellow solid. Yield $83 \%$. M.p. $230-232{ }^{\circ} \mathrm{C}$. FT-IR (KBr): $v 3283,1623,1525,1462,1130,753 \mathrm{~cm}^{-1} .{ }^{1} \mathrm{H}$ NMR (300 MHz, $\mathrm{CDCl}_{3}+$ DMSO- $\left.d_{6}\right): \delta 8.75(\mathrm{~s}, 1 \mathrm{H}$, imine), 8.25 (s, $1 \mathrm{H}, \mathrm{Ar}-\mathrm{H}), 7.91(\mathrm{~s}, 1 \mathrm{H}, \mathrm{Ar}-\mathrm{H}), 7.63\left(\mathrm{dd}, 1 \mathrm{H}, J_{1}=8.4 \mathrm{~Hz}\right.$, $\left.J_{2}=18 \mathrm{~Hz}, \mathrm{Ar}-\mathrm{H}\right), 7.57(\mathrm{~s}, 1 \mathrm{H}, \mathrm{Ar}-\mathrm{H}), 7.55-7.49(\mathrm{~m}, 1 \mathrm{H}$, Ar-H), 7.06 (d, 2H, $J=7.7 \mathrm{~Hz}, \operatorname{Ar}-\mathrm{H}), 6.75(\mathrm{t}, 1 \mathrm{H}, J=6.6$ $\mathrm{Hz}, \mathrm{Ar}-\mathrm{H}), 2.46\left(\mathrm{~s}, 3 \mathrm{H}, \mathrm{CH}_{3}\right) .{ }^{13} \mathrm{C} \mathrm{NMR}\left(75 \mathrm{MHz}, \mathrm{CDCl}_{3}+\right.$ DMSO- $\left.d_{6}\right): \delta 184.1,173.0,169.6,152.2,150.4,133.3,129.2$, $122.8,122.5,121.2,117.5,116.4,113.0,112.1,18.7$. ESI-MS: $m / z[\mathrm{M}+\mathrm{H}]^{+} 297$.

(E)-3-((2-(3-Fluorophenyl)hydrazono)methyl)-6-methyl-4H-chromen-4-one (3n)

Yellow solid. Yield $67 \%$. M.p. $261-263{ }^{\circ} \mathrm{C} .{ }^{1} \mathrm{H}$ NMR (300 MHz, $\mathrm{CDCl}_{3}+$ DMSO- $\left.d_{6}\right): \delta 8.57(\mathrm{~s}, 1 \mathrm{H}$, imine), 8.18 (s, $1 \mathrm{H}, \mathrm{Ar}-\mathrm{H}), 7.87(\mathrm{~s}, 1 \mathrm{H}, \mathrm{Ar}-\mathrm{H}), 7.52(\mathrm{~d}, 1 \mathrm{H}, J=8.0 \mathrm{~Hz}$,
Ar-H), $7.43(\mathrm{~d}, 1 \mathrm{H}, J=8.0 \mathrm{~Hz}, \mathrm{Ar}-\mathrm{H}), 7.00-6.93(\mathrm{~m}, 2 \mathrm{H}$, $\mathrm{Ar}-\mathrm{H}), 6.67(\mathrm{t}, 2 \mathrm{H}, J=6.0 \mathrm{~Hz}, \mathrm{Ar}-\mathrm{H}), 2.43\left(\mathrm{~s}, 3 \mathrm{H}, \mathrm{CH}_{3}\right) .{ }^{13} \mathrm{C}$ NMR $\left(75 \mathrm{MHz}, \mathrm{CDCl}_{3}+\right.$ DMSO- $\left.d_{6}\right): \delta 175.3,154.5,153.1$, 147.6, 135.8, 131.1, 129.9, 124.8, 123.4, 119.5, 118.9, 108.6, 105.3, 98.9, 20.9. ESI-MS: $m / z[\mathrm{M}+\mathrm{H}]^{+} 297$.

(E)-3-((2-(4-Fluorophenyl)hydrazono)methyl)-6-methyl-4H-chromen-4-one (3o)

Yellow solid. Yield 72\%. M.p. $264-266^{\circ} \mathrm{C} .{ }^{1} \mathrm{H}$ NMR (300 MHz, $\mathrm{CDCl}_{3}+$ DMSO- $\left.d_{6}\right): \delta 8.64(\mathrm{~s}, 1 \mathrm{H}$, imine), 7.98 (s, $1 \mathrm{H}, \mathrm{Ar}-\mathrm{H}), 7.92(\mathrm{~s}, 1 \mathrm{H}, \mathrm{Ar}-\mathrm{H}), 7.58\left(\mathrm{dd}, 1 \mathrm{H}, J_{1}=8.6 \mathrm{~Hz}, J_{2}=\right.$ $1.8 \mathrm{~Hz}, \mathrm{Ar}-\mathrm{H}), 7.50(\mathrm{~d}, 1 \mathrm{H}, J=8.4 \mathrm{~Hz}, \mathrm{Ar}-\mathrm{H}), 7.07-7.01(\mathrm{~m}$, $2 \mathrm{H}, \mathrm{Ar}-\mathrm{H}), 6.95(\mathrm{t}, 2 \mathrm{H}, J=8.4 \mathrm{~Hz}, \mathrm{Ar}-\mathrm{H}), 2.47\left(\mathrm{~s}, 3 \mathrm{H}, \mathrm{CH}_{3}\right)$. ${ }^{13} \mathrm{C}$ NMR $\left(75 \mathrm{MHz}, \mathrm{CDCl}_{3}+\mathrm{DMSO}-d_{6}\right): \delta 189.4,161.2$, 157.9, 157.0, 140.6, 134.4, 133.8, 129.7, 129.2, 126.4, 121.7, 119.8, 115.9, 114.4, 114.7, 18.6. ESI-MS: $m / z[\mathrm{M}+\mathrm{H}]^{+} 297$.

(E)-3-((2-(4-Bromophenyl)hydrazono)methyl)-6-methyl-4H-chromen-4-one (3p)

Yellow solid. Yield $78 \%$. M.p. $246-248{ }^{\circ} \mathrm{C}$. FT-IR (KBr): $v 3265,2977,1622,1571,1491,1206,872,748 \mathrm{~cm}^{-1}$. ${ }^{1} \mathrm{H}$ NMR $\left(300 \mathrm{MHz}, \mathrm{CDCl}_{3}+\mathrm{DMSO}-d_{6}\right): \delta 8.56(\mathrm{~s}, 1 \mathrm{H}$, imine), 7.97 (s, 1H, Ar-H), 7.92 (s, 1H, Ar-H), 7.52 (d, 1H, $J=7.0 \mathrm{~Hz}, \mathrm{Ar}-\mathrm{H}), 7.44(\mathrm{~d}, 1 \mathrm{H}, J=8.0 \mathrm{~Hz}, \mathrm{Ar}-\mathrm{H}), 7.02(\mathrm{t}$, $1 \mathrm{H}, J=7.0 \mathrm{~Hz}, \mathrm{Ar}-\mathrm{H}), 6.85(\mathrm{~s}, 1 \mathrm{H}, \mathrm{Ar}-\mathrm{H}), 6.81(\mathrm{~d}, 1 \mathrm{H}, J=$ $8.0 \mathrm{~Hz}, \mathrm{Ar}-\mathrm{H}), 6.53$ (d, $1 \mathrm{H}, J=7.0 \mathrm{~Hz}, \mathrm{Ar}-\mathrm{H}) .{ }^{13} \mathrm{C}$ NMR $(75$ $\left.\mathrm{MHz}, \mathrm{CDCl}_{3}+\mathrm{DMSO}-d_{6}\right): \delta 171.3,154.6,151.0,148.5$, 144.0, 137.7, 133.3, 106.9, 40.2. ESI-MS: $m / z[\mathrm{M}+\mathrm{H}]^{+} 357$.

(E)-6-Chloro-3-((2-phenylhydrazono) methyl)-4Hchromen-4-one (3q)

Yellow solid. Yield 72\%. M.p. $229-231{ }^{\circ} \mathrm{C} .{ }^{1} \mathrm{H}$ NMR (300 MHz, $\mathrm{CDCl}_{3}+$ DMSO- $\left.d_{6}\right): \delta 8.68(\mathrm{~s}, 1 \mathrm{H}$, imine), 8.08 $(\mathrm{d}, 1 \mathrm{H}, J=3.2 \mathrm{~Hz}, \mathrm{Ar}-\mathrm{H}), 7.97(\mathrm{~s}, 1 \mathrm{H}, \mathrm{Ar}-\mathrm{H}), 7.74\left(\mathrm{dd}, 1 \mathrm{H}, J_{1}\right.$ $\left.=8.8 \mathrm{~Hz}, J_{2}=2.6 \mathrm{~Hz}, \mathrm{Ar}-\mathrm{H}\right), 7.65(\mathrm{~d}, 1 \mathrm{H}, J=8.8 \mathrm{~Hz}, \mathrm{Ar}-\mathrm{H})$, $7.19(\mathrm{t}, 2 \mathrm{H}, J=8.4 \mathrm{~Hz}, \mathrm{Ar}-\mathrm{H}), 7.06(\mathrm{~d}, 2 \mathrm{H}, J=7.5 \mathrm{~Hz}, \mathrm{Ar}-\mathrm{H})$, $6.75(\mathrm{t}, 1 \mathrm{H}, J=7.1 \mathrm{~Hz}, \mathrm{Ar}-\mathrm{H})$. ESI-MS: $m / z[\mathrm{M}+\mathrm{H}]^{+} 299$.

(E)-6-Chloro-3-((2-m-tolylhydrazono $)$ methyl $)-4 H$ chromen-4-one (3r)

Yellow solid. Yield 57\%. M.p. $215-217{ }^{\circ} \mathrm{C}$. FT-IR (KBr): $v 3276,2920,1640,1608,1460,1297,1160,813,772$ $\mathrm{cm}^{-1} .{ }^{1} \mathrm{H}$ NMR $\left(300 \mathrm{MHz}, \mathrm{CDCl}_{3}+\mathrm{DMSO}_{-} d_{6}\right): \delta 8.56(\mathrm{~s}$, $1 \mathrm{H}$, imine), $8.02(\mathrm{~s}, 1 \mathrm{H}, \mathrm{Ar}-\mathrm{H}), 7.86(\mathrm{~s}, 1 \mathrm{H}, \mathrm{Ar}-\mathrm{H}), 7.60$ $\left(\mathrm{dd}, 2 \mathrm{H}, J_{1}=6.8 \mathrm{~Hz}, J_{2}=8.8 \mathrm{~Hz}, \mathrm{Ar}-\mathrm{H}\right), 6.96(\mathrm{t}, 1 \mathrm{H}, J=7.8$ $\mathrm{Hz}, \mathrm{Ar}-\mathrm{H}), 6.79$ (s, 1H, Ar-H), 6.75 (d, $1 \mathrm{H}, J=7.8 \mathrm{~Hz}$, Ar-H), 6.48 (d, $1 \mathrm{H}, J=7.8 \mathrm{~Hz}, \mathrm{Ar}-\mathrm{H}) .{ }^{13} \mathrm{C}$ NMR $(75 \mathrm{MHz}$, $\mathrm{CDCl}_{3}+$ DMSO- $\left.d_{6}\right): \delta 179.6,169.4,161.6,159.2,154.7$, 153.2, 150.3, 149.5, 148.9, 148.1, 144.4, 143.1, 142.3, 139.9, 139.3, 136.3, 40.8. ESI-MS: $m / z[\mathrm{M}+\mathrm{H}]^{+} 313$.

(E)-6-Chloro-3-((2-(4-methoxyphenyl)hydrazono) methyl)-4H-chromen-4-one (3s)

Yellow solid. Yield $61 \%$. M.p. $219-221{ }^{\circ} \mathrm{C}$. FT-IR (KBr): $v$ 3271, 2901, 1621, 1570, 1464, 1228, $1042 \mathrm{~cm}^{-1} .{ }^{1} \mathrm{H}$ NMR $\left(300 \mathrm{MHz}, \mathrm{CDCl}_{3}+\mathrm{DMSO}-d_{6}\right): \delta 8.56(\mathrm{~s}, 1 \mathrm{H}$, 
imine), $8.08(\mathrm{~s}, 1 \mathrm{H}, \mathrm{Ar}-\mathrm{H}), 7.88(\mathrm{~s}, 1 \mathrm{H}, \mathrm{Ar}-\mathrm{H}), 7.68(\mathrm{~d}, 1 \mathrm{H}$, $J=8.8 \mathrm{~Hz}, \mathrm{Ar}-\mathrm{H}), 7.56(\mathrm{~d}, 1 \mathrm{H}, J=8.8 \mathrm{~Hz}, \mathrm{Ar}-\mathrm{H}), 6.96(\mathrm{~d}$, $2 \mathrm{H}, J=8.4 \mathrm{~Hz}, \mathrm{Ar}-\mathrm{H}), 6.74(\mathrm{~d}, 2 \mathrm{H}, J=8.4 \mathrm{~Hz}, \mathrm{Ar}-\mathrm{H}), 3.72$ $\left(\mathrm{s}, 3 \mathrm{H}, \mathrm{OCH}_{3}\right) .{ }^{13} \mathrm{C}$ NMR $\left(75 \mathrm{MHz}, \mathrm{CDCl}_{3}+\mathrm{DMSO}-d_{6}\right): \delta$ 173.2, 164.2, 150.4, 146.2, 134.4, 132.2, 129.7, 124.3, 115.9, 117.2, 119.8, 53.2. ESI-MS: $m / z[\mathrm{M}+\mathrm{H}]^{+} 329$.

(E)-6-Bromo-3-((2-phenylhydrazono) methyl)-4Hchromen-4-one (3t)

Yellow solid. Yield $72 \%$. M.p. $218-220{ }^{\circ} \mathrm{C}$. FT-IR $(\mathrm{KBr}): v 3283,1623,1525,1462,1258,1182,1027,753$ $\mathrm{cm}^{-1} .{ }^{1} \mathrm{H}$ NMR $\left(300 \mathrm{MHz}, \mathrm{CDCl}_{3}+\mathrm{DMSO}-d_{6}\right): \delta 8.61(\mathrm{~s}$, $1 \mathrm{H}$, imine), $8.24(\mathrm{~d}, 1 \mathrm{H}, J=1.3 \mathrm{~Hz}, \mathrm{Ar}-\mathrm{H}), 7.94(\mathrm{~s}, 1 \mathrm{H}$, $\mathrm{Ar}-\mathrm{H}), 7.82\left(\mathrm{dd}, 1 \mathrm{H}, J_{1}=6.4 \mathrm{~Hz}, J_{2}=8.8 \mathrm{~Hz}, \mathrm{Ar}-\mathrm{H}\right), 7.53(\mathrm{~d}$, $1 \mathrm{H}, J=8.8 \mathrm{~Hz}$, Ar-H), 7.16 (t, $2 \mathrm{H}, J=7.5 \mathrm{~Hz}$, Ar- $\mathrm{H}$ ), 7.02 $(\mathrm{d}, 2 \mathrm{H}, J=7.7 \mathrm{~Hz}, \mathrm{Ar}-\mathrm{H}), 6.72(\mathrm{t}, 1 \mathrm{H}, J=7.1 \mathrm{Ar}-\mathrm{H})$.

(E)-6-Bromo-3-((2-m-tolylhydrazono $)$ methyl $)-4 H$ chromen-4-one (3u)

Yellow solid. Yield $81 \%$. M.p. $240-242{ }^{\circ} \mathrm{C}$. FT-IR (KBr): $v 3276,2918,1639,1602,1454,1296,1159,813,773$ $\mathrm{cm}^{-1} \cdot{ }^{1} \mathrm{H}$ NMR $\left(300 \mathrm{MHz}, \mathrm{CDCl}_{3}+\mathrm{DMSO}_{-} d_{6}\right): \delta 8.70(\mathrm{~s}$, $1 \mathrm{H}$, imine), $8.23(\mathrm{~d}, 1 \mathrm{H}, J=2.5 \mathrm{~Hz}, \mathrm{Ar}-\mathrm{H}), 7.94(\mathrm{~s}, 1 \mathrm{H}$, $\mathrm{Ar}-\mathrm{H}), 7.90\left(\mathrm{dd}, 1 \mathrm{H}, J_{1}=8.8 \mathrm{~Hz}, J_{2}=6.8 \mathrm{~Hz}, \mathrm{Ar}-\mathrm{H}\right), 7.63(\mathrm{~d}$, $1 \mathrm{H}, J=8.2 \mathrm{~Hz}, \mathrm{Ar}-\mathrm{H}), 7.07$ (t, $1 \mathrm{H}, J=7.8 \mathrm{~Hz}, \mathrm{Ar}-\mathrm{H}), 6.89$ $(\mathrm{s}, 1 \mathrm{H}, \mathrm{Ar}-\mathrm{H}), 6.84(\mathrm{~d}, 1 \mathrm{H}, J=8.3 \mathrm{~Hz}, \mathrm{Ar}-\mathrm{H}), 6.57(\mathrm{~d}, 1 \mathrm{H}, J$ $=7.5 \mathrm{~Hz}$, Ar-H). ESI-MS: $m / z[\mathrm{M}+\mathrm{H}]^{+} 357$.

(E)-6-Bromo-3-((2-(4-methoxyphenyl)hydrazono)methyl)-4H-chromen-4-one (3v)

Yellow solid. Yield $66 \%$. M.p. $245-247{ }^{\circ} \mathrm{C}$. FT-IR (KBr): $v 3271,2901,1621,1570,1464,1228,1042,827,791$ $\mathrm{cm}^{-1} .{ }^{1} \mathrm{H}$ NMR $\left(75 \mathrm{MHz}, \mathrm{CDCl}_{3}+\mathrm{DMSO}-d_{6}\right): \delta 8.58(\mathrm{~s}, 1 \mathrm{H}$, imine), $8.16(\mathrm{~d}, 1 \mathrm{H}, J=8.8 \mathrm{~Hz}, \mathrm{Ar}-\mathrm{H}), 8.02(\mathrm{~d}, 1 \mathrm{H}, J=7.8$ $\mathrm{Hz}, \mathrm{Ar}-\mathrm{H}), 7.74$ (s, 1H, Ar-H), 7.72-7.66 (m, 1H, Ar-H), 7.56-7.40 (m, 2H, Ar-H), 7.23 (d, $2 \mathrm{H}, J=8.4 \mathrm{~Hz}, \mathrm{Ar}-\mathrm{H})$, $6.96(\mathrm{~d}, 2 \mathrm{H}, J=8.4 \mathrm{~Hz}, \mathrm{Ar}-\mathrm{H}), 3.20\left(\mathrm{~s}, 3 \mathrm{H}, \mathrm{OCH}_{3}\right) .{ }^{13} \mathrm{C} \mathrm{NMR}$ $\left(75 \mathrm{MHz}, \mathrm{CDCl}_{3}+\mathrm{DMSO}_{6} d_{6}\right): \delta 172.8,148.3,141.1,137.0$, 132.2, 130.0, 124.8, 120.5, 119.7, 119.3, 113.8, 113.7, 54.7.

(E)-6-((2-Phenylhydrazono) methyl)-5H-furo [3,2-g] chromen-5-one (3w)

Yellow solid. Yield $72 \%$. M.p. $235-236{ }^{\circ} \mathrm{C}$. FT-IR (KBr): $v 3270,1631,1592,1275,1173,1044,750 \mathrm{~cm}^{-1} .{ }^{1} \mathrm{H}$ NMR $\left(300 \mathrm{MHz}, \mathrm{CDCl}_{3}+\mathrm{DMSO}-d_{6}\right): \delta 8.81(\mathrm{~s}, 1 \mathrm{H}$, imine), $8.42(\mathrm{~s}, 1 \mathrm{H}, \mathrm{Ar}-\mathrm{H}), 8.20(\mathrm{~d}, 1 \mathrm{H}, J=8.0 \mathrm{~Hz}, \mathrm{Ar}-\mathrm{H})$, $8.00(\mathrm{~s}, 2 \mathrm{H}, \mathrm{Ar}-\mathrm{H}), 7.20$ (t, 3H, $J=8.1 \mathrm{~Hz}, \mathrm{Ar}-\mathrm{H}), 7.06$ (d, $2 \mathrm{H}, J=7.7 \mathrm{~Hz}, \mathrm{Ar}-\mathrm{H}), 6.74(\mathrm{t}, 1 \mathrm{H}, J=7.1 \mathrm{~Hz}, \mathrm{Ar}-\mathrm{H}) \cdot{ }^{13} \mathrm{C}$ NMR (75 MHz, $\mathrm{CDCl}_{3}+$ DMSO- $\left.d_{6}\right): \delta 190.6,159.2,144.5$, 141.1, 137.9, 129.7, 128.4, 127.8, 126.4, 123.8, 122.2, 119.1, 118.4, 116.4, 113.8, 105.9, 98.4. ESI-MS: $m / z[\mathrm{M}+\mathrm{H}]^{+} 305$.

(E)-6-((2-m-Tolylhydrazono)methyl)-5H-furo[3,2-g] chromen-5-one (3x)

Yellow solid. Yield $81 \%$. M.p. $238-240{ }^{\circ} \mathrm{C}$. FT-IR (KBr): $v 3265,2793,1623,1484,1171,816,779 \mathrm{~cm}^{-1} .{ }^{1} \mathrm{H}$
NMR $\left(300 \mathrm{MHz}, \mathrm{CDCl}_{3}+\right.$ DMSO- $\left.d_{6}\right): \delta 9.00(\mathrm{~s}, 1 \mathrm{H}$, imine), $8.26(\mathrm{~s}, 1 \mathrm{H}, \mathrm{Ar}-\mathrm{H}), 8.21(\mathrm{~s}, 1 \mathrm{H}, \mathrm{Ar}-\mathrm{H}), 7.77(\mathrm{~d}, 1 \mathrm{H}$, $J=1.8 \mathrm{~Hz}, \mathrm{Ar}-\mathrm{H}), 7.22(\mathrm{~d}, 1 \mathrm{H}, J=8.0 \mathrm{~Hz}, \mathrm{Ar}-\mathrm{H}), 7.40(\mathrm{~d}$, $1 \mathrm{H}, J=8.0 \mathrm{~Hz}, \mathrm{Ar}-\mathrm{H}), 7.19$ (d, $2 \mathrm{H}, J=7.3 \mathrm{~Hz}, \mathrm{Ar}-\mathrm{H}), 7.10$ (s, $1 \mathrm{H}, \mathrm{Ar}-\mathrm{H}), 6.91(\mathrm{~s}, 1 \mathrm{H}, \mathrm{Ar}-\mathrm{H}), 2.45\left(\mathrm{~s}, 1 \mathrm{H}, \mathrm{CH}_{3}\right) \cdot{ }^{13} \mathrm{C}$ NMR (75 MHz, $\mathrm{CDCl}_{3}+$ DMSO- $\left.d_{6}\right): \delta 189.7,158.0,156.8$, 144.0, 140.5, 137.6, 129.5, 127.5, 126.4, 123.3, 121.6, 118.3, $116.5,114.9,105.5,97.6,19.5$. ESI-MS: $m / z[\mathrm{M}+\mathrm{H}]^{+} 319$.

(E)-3-((2-Phenylhydrazono) methyl)-4H-furo[2,3-h] chromen-4-one (3y)

Yellow solid. Yield $85 \%$. M.p. $236-238{ }^{\circ} \mathrm{C}$. FT-IR (KBr): $v$ 3270, 1631, 1592, 1275, 1173, 1044, $750 \mathrm{~cm}^{-1} .{ }^{1} \mathrm{H}$ NMR $\left(300 \mathrm{MHz}, \mathrm{CDCl}_{3}+\right.$ DMSO- $\left.d_{6}\right): \delta 8.66(\mathrm{~s}, 1 \mathrm{H}$, imine), 8.08 (d, $1 \mathrm{H}, J=8.3 \mathrm{~Hz}, \mathrm{Ar}-\mathrm{H}), 7.96-8.00(\mathrm{~m}, 3 \mathrm{H}$, Ar-H), $7.62(\mathrm{~d}, 1 \mathrm{H}, J=8.8 \mathrm{~Hz}, \operatorname{Ar}-\mathrm{H}), 7.05(\mathrm{t}, 1 \mathrm{H}, J=7.8$ $\mathrm{Hz}, \mathrm{Ar}-\mathrm{H}), 6.86(\mathrm{~s}, 1 \mathrm{H}, \mathrm{Ar}-\mathrm{H}), 6.84(\mathrm{~d}, 1 \mathrm{H}, J=7.8 \mathrm{~Hz}$, Ar-H), $6.54(\mathrm{~d}, 1 \mathrm{H}, J=7.8 \mathrm{~Hz}, \mathrm{Ar}-\mathrm{H}) .{ }^{13} \mathrm{C}$ NMR $(75 \mathrm{MHz}$, $\left.\mathrm{CDCl}_{3}+\mathrm{DMSO}_{-} d_{6}\right): \delta 190.4,157.4,143.6,140.9,129.5$, 128.2, 127.7, 126.6, 126.2, 120.6, 119.8, 118.2, 113.6, 113.1, 103.6, 102.6: ESI-MS: $m / z[\mathrm{M}+\mathrm{H}]^{+} 305$

(E)-3-((2-m-Tolylhydrazono)methyl)-4H-furo[2,3-h] chromen-4-one (3z)

Yellow solid. Yield $42 \%$. M.p. $239-241{ }^{\circ} \mathrm{C}$. FT-IR (KBr): v 3270, 1631, 1592, 1275, 1173, 1044, $750 \mathrm{~cm}^{-1} .{ }^{1} \mathrm{H}$ NMR $\left(300 \mathrm{MHz}, \mathrm{CDCl}_{3}+\mathrm{DMSO}-d_{6}\right): \delta 8.89(\mathrm{~s}, 1 \mathrm{H}$, imine), 8.08 (d, $1 \mathrm{H}, J=8.3 \mathrm{~Hz}, \mathrm{Ar}-\mathrm{H}), 7.95(\mathrm{~d}, 1 \mathrm{H}, J=8.8$ $\mathrm{Hz}, \mathrm{Ar}-\mathrm{H}), 7.77$ (s, 1H, Ar-H), $7.72(\mathrm{~s}, 1 \mathrm{H}, \mathrm{Ar}-\mathrm{H}), 7.68(\mathrm{~d}$, $1 \mathrm{H}, J=7.8 \mathrm{~Hz}, \operatorname{Ar}-\mathrm{H}), 7.38(\mathrm{t}, 1 \mathrm{H}, J=7.7 \mathrm{Ar}-\mathrm{H}), 7.18(\mathrm{t}$, $2 \mathrm{H}, J=8.6 \mathrm{~Hz}, \mathrm{Ar}-\mathrm{H}), 7.03$ (s, $1 \mathrm{H}, \mathrm{Ar}-\mathrm{H}), 2.43$ (s, $3 \mathrm{H}$, $\left.\mathrm{CH}_{3}\right) .{ }^{13} \mathrm{C}$ NMR $\left(75 \mathrm{MHz}, \mathrm{CDCl}_{3}+\mathrm{DMSO}_{6} d_{6}\right): \delta 189.4$, 157.1, 155.8, 143.5, 140.3, 137.3, 137.0, 129.2, 127.4, 126.1, $121.1,117.9,114.6,112.6,102.8,101.9,19.0$. ESI-MS: $m / z$ $[\mathrm{M}+\mathrm{H}]^{+} 319$.

\section{3. General Procedure for the Preparation of Pyrazolecarboxylates $5 \mathbf{a}-\mathbf{x}$}

The $N$-bromosuccinimide $(0.267 \mathrm{~g}, 1.5 \mathrm{mmol})$ was added to a stirred solution of (E)-3-((2-phenylhydrazono) methyl)-4H-chromen-4-one $3 \mathrm{a}(0.264 \mathrm{~g}, 1 \mathrm{mmol})$ in benzene at room temperature. The reaction was monitored by TLC, after completion of the reaction, the solvent was removed under reduced pressure and the crude product was used for further reaction without purification. The dimethyl acetylenedicarboxylate $(4 \mathbf{a}, 0.168 \mathrm{~g}, 1.2 \mathrm{mmol})$ was added to a stirred solution of bromohydrazone derivative in acetonitrile $(3 \mathrm{~mL})$ at room temperature under nitrogen atmosphere. The reaction mixture was refluxed for $12 \mathrm{~h}$ and after completion of the reaction (TLC), the solvent was removed under reduced pressure, and the resulting residue was purified by column chromatography using silica gel (60-120, hexane-ethylacetate, 9:1) affording $\mathbf{5} \mathbf{a}$ as a colourless solid. Similarly, the compounds $5 \mathbf{b}-\mathbf{x}$ were prepared from the corresponding $(E)-3-((2-$ phenylhydrazo- 
no)methyl)-4H-chromen-4-ones $\mathbf{3 b}-\mathbf{c}, \mathbf{3 e}, \mathbf{3 h}-\mathbf{l}, \mathbf{3 n}, \mathbf{3} \mathbf{p}-\mathbf{v}$ with acetylenedicarboxylates $\mathbf{4 a}-\mathbf{b}$ under optimized conditions.

Dimethyl 3-(4-Oxo-4H-chromen-3-yl)-1-phenyl-1Hpyrazole-4,5-dicarboxylate (5a)

Colourless solid. Yield 78\%, M.p. $144-145^{\circ} \mathrm{C}$. FT-IR $(\mathrm{KBr}): v 2923,1721,1656,1547,1462,1245,1009,755$ $\mathrm{cm}^{-1} .{ }^{1} \mathrm{H}$ NMR $\left(300 \mathrm{MHz}, \mathrm{CDCl}_{3}\right): \delta 8.30\left(\mathrm{dd}, 1 \mathrm{H}, J_{1}=7.8\right.$ $\left.\mathrm{Hz}, J_{2}=6.4 \mathrm{~Hz}, \mathrm{Ar}-\mathrm{H}\right), 8.25(\mathrm{~s}, 1 \mathrm{H}, \mathrm{Ar}-\mathrm{H}), 7.70(\mathrm{t}, 1 \mathrm{H}, J=$ $1.8 \mathrm{~Hz}, \operatorname{Ar}-\mathrm{H}), 7.52-7.41(\mathrm{~m}, 7 \mathrm{H}, \operatorname{Ar}-\mathrm{H}), 3.85(\mathrm{~s}, 3 \mathrm{H}$, $\left.\mathrm{OCH}_{3}\right), 3.79\left(\mathrm{~s}, 3 \mathrm{H}, \mathrm{OCH}_{3}\right) \cdot{ }^{13} \mathrm{C} \mathrm{NMR}\left(75 \mathrm{MHz}, \mathrm{CDCl}_{3}\right): \delta$ $174.5,162.2,160.1,156.2,154.1,144.1,139.0,133.5,129.0$, $128.8,126.5,125.3,124.3,118.1,52.9,51.8$. ESI-MS: $m / z$ $[\mathrm{M}+\mathrm{H}]^{+} 405$.

Dimethyl 3-(4-Oxo-4H-chromen-3-yl)-1-m-tolyl-1Hpyrazole-4,5-dicarboxylate (5b)

Pale yellow solid. Yield $67 \%$. M.p. $156-158^{\circ} \mathrm{C}$. FT-IR (KBr): $v 2925,1732,1657,1463,1234,1149,762 \mathrm{~cm}^{-1} .{ }^{1} \mathrm{H}$ NMR $\left(300 \mathrm{MHz}, \mathrm{CDCl}_{3}\right): \delta 8.28\left(\mathrm{dd}, 1 \mathrm{H}, J_{1}=7.4 \mathrm{~Hz}, J_{2}=\right.$ $6.0 \mathrm{~Hz}, \mathrm{Ar}-\mathrm{H}), 8.23$ (s, $1 \mathrm{H}, \mathrm{Ar}-\mathrm{H}), 7.68$ (t, $1 \mathrm{H}, J=1.5 \mathrm{~Hz}$, Ar-H), 7.60 (d, $2 \mathrm{H}, J=8.6 \mathrm{~Hz}, \mathrm{Ar}-\mathrm{H}), 7.50-7.40$ (m, 2H, Ar-H), 7.34 (s, 2H, Ar-H), 7.28-7.21 (m, 3H, Ar-H), 3.86 $\left(\mathrm{s}, 3 \mathrm{H}, \mathrm{OCH}_{3}\right), 3.78\left(\mathrm{~s}, 3 \mathrm{H}, \mathrm{OCH}_{3}\right), 2.45\left(\mathrm{~s}, 3 \mathrm{H}, \mathrm{CH}_{3}\right) .{ }^{13} \mathrm{C}$ NMR $\left(75 \mathrm{MHz}, \mathrm{CDCl}_{3}\right): \delta 173.0,166.7,160.4,154.5,154.2$, 145.0, 143.3, 139.0, 136.5, 135.3, 134.9, 129.8, 128.9, 125.7, $125.1,123.9,121.3,117.9,117.6,53.0,52.0,21.0$. ESI-MS: $m / z[\mathrm{M}+\mathrm{H}]^{+} 419$.

Dimethyl 1-(4-Methoxyphenyl)-3-(4-oxo-4H-chromen3-yl)-1H-pyrazole-4,5-dicarboxylate (5c)

Colourless solid. Yield 57\%. M.p. $149-151^{\circ} \mathrm{C}$. FT-IR (KBr): $v$ 2947, 1727, 1603, 1440, 1240, $1103 \mathrm{~cm}^{-1} .{ }^{1} \mathrm{H}$ NMR $\left(300 \mathrm{MHz}, \mathrm{CDCl}_{3}\right): \delta 8.28\left(\mathrm{dd}, 1 \mathrm{H}, J_{1}=7.8 \mathrm{~Hz}, J_{2}=6.8 \mathrm{~Hz}\right.$, Ar-H), 8.23 (s, 1H, Ar-H), 7.68 (t, $1 \mathrm{H}, J=2.2 \mathrm{~Hz}$, Ar-H), 7.50-7.38 (m, 4H, Ar-H), 6.94 (d, 2H, J=8.8 Hz, Ar-H), $3.86\left(\mathrm{~s}, 3 \mathrm{H}, \mathrm{OCH}_{3}\right), 3.84\left(\mathrm{~s}, 3 \mathrm{H}, \mathrm{OCH}_{3}\right), 3.74(\mathrm{~s}, 3 \mathrm{H}$, $\left.\mathrm{OCH}_{3}\right)$. ESI-MS: $m / z[\mathrm{M}+\mathrm{H}]^{+} 435$.

Dimethyl 1-(2-Fluorophenyl)-3-(4-oxo-4H-chromen-3yl)-1 $H$-pyrazole-4,5-dicarboxylate (5d)

Pale yellow solid. Yield 72\%. FT-IR (KBr): $v$ 2950, 2856, 1733, 1655, 1464, 1244, $1125 \mathrm{~cm}^{-1} .{ }^{1} \mathrm{H}$ NMR $(300$ $\left.\mathrm{MHz}, \mathrm{CDCl}_{3}\right): \delta 8.30(\mathrm{~s}, 1 \mathrm{H}$, imine), $8.26(\mathrm{~d}, 1 \mathrm{H}, J=7.5 \mathrm{~Hz}$, Ar-H), 7.68 (t, $1 \mathrm{H}, J=2.4 \mathrm{~Hz}, \mathrm{Ar}-\mathrm{H}), 7.56(\mathrm{t}, 1 \mathrm{H}, J=1.5$ $\mathrm{Hz}, \operatorname{Ar}-\mathrm{H}), 7.50-7.40(\mathrm{~m}, 3 \mathrm{H}, \mathrm{Ar}-\mathrm{H}), 7.32-7.16(\mathrm{~m}, 2 \mathrm{H}$, $\mathrm{Ar}-\mathrm{H}), 3.82\left(\mathrm{~s}, 3 \mathrm{H}, \mathrm{OCH}_{3}\right), 3.80\left(\mathrm{~s}, 3 \mathrm{H}, \mathrm{OCH}_{3}\right) \cdot{ }^{13} \mathrm{C} \mathrm{NMR}$ $\left(75 \mathrm{MHz}, \mathrm{CDCl}_{3}\right): \delta 174.8,162.9,158.9,157.6,154.4$, $144.2,133.8,130.9,127.9,126.1,125.4,124.6,118.0,116.3$, 116.0, 52.7, 52.1. ESI-MS: $m / z[\mathrm{M}+\mathrm{H}]^{+} 423$.

Dimethyl 1-(4-Bromophenyl)-3-(4-oxo-4H-chromen-3yl)-1H-pyrazole-4,5-dicarboxylate (5e)

Colourless solid. Yield 57\%. M.p. $136-138^{\circ} \mathrm{C}$. FT-IR (KBr): $v 2923,1732,1655,1463,1272,1157,769 \mathrm{~cm}^{-1} .{ }^{1} \mathrm{H}$
$\operatorname{NMR}\left(300 \mathrm{MHz}, \mathrm{CDCl}_{3}\right): \delta 8.28\left(\mathrm{dd}, 1 \mathrm{H}, J_{1}=7.8 \mathrm{~Hz}, J_{2}=\right.$ $6.6 \mathrm{~Hz}, \mathrm{Ar}-\mathrm{H}), 8.23(\mathrm{~s}, 1 \mathrm{H}, \mathrm{Ar}-\mathrm{H}), 7.68(\mathrm{t}, 1 \mathrm{H}, J=2.6 \mathrm{~Hz}$, Ar-H), 7.60 (d, 2H, J = 8.6 Hz, Ar-H), 7.50-7.42 (m, 2H, Ar-H), $7.38(\mathrm{~d}, 2 \mathrm{H}, J=8.6 \mathrm{~Hz}, \mathrm{Ar}-\mathrm{H}), 3.86\left(\mathrm{~s}, 3 \mathrm{H}, \mathrm{OCH}_{3}\right)$, $3.78\left(\mathrm{~s}, 3 \mathrm{H}, \mathrm{OCH}_{3}\right) .{ }^{13} \mathrm{C} \mathrm{NMR}\left(75 \mathrm{MHz}, \mathrm{CDCl}_{3}\right): \delta 174.4$, $162.1,159.9,154.1,144.4,136.1,133.6,132.2,126.6,126.0$, $125.4,124.4,118.1,117.8,117.4,53.0,52.0$.

Dimethyl 1-(2,4-Dichlorophenyl)-3-(4-oxo-4H-chromen-3-yl)-1H-pyrazole-4,5-dicarboxylate (5f)

Brown solid. Yield $66 \%$. M.p. $129-131^{\circ} \mathrm{C}$. FT-IR ( $\left.\mathrm{KBr}\right)$ : $v 2793,1622,1484,1301,1171,779 \mathrm{~cm}^{-1} .{ }^{1} \mathrm{H}$ NMR (300 $\left.\mathrm{MHz}, \mathrm{CDCl}_{3}\right): \delta 8.28\left(\mathrm{dd}, 1 \mathrm{H}, J_{1}=7.8 \mathrm{~Hz}, J_{2}=6.8 \mathrm{~Hz}, \mathrm{Ar}-\mathrm{H}\right)$, $8.24(\mathrm{~s}, 1 \mathrm{H}$, imine), $7.69(\mathrm{t}, 1 \mathrm{H}, J=1.6 \mathrm{~Hz}, \mathrm{Ar}-\mathrm{H}), 7.50(\mathrm{~d}, 1 \mathrm{H}$, $J=7.8 \mathrm{~Hz}, \mathrm{Ar}-\mathrm{H}), 7.46-7.42(\mathrm{~m}, 4 \mathrm{H}, \mathrm{Ar}-\mathrm{H}), 3.92$ (s, 3H, $\left.\mathrm{OCH}_{3}\right), 3.80\left(\mathrm{~s}, 3 \mathrm{H}, \mathrm{OCH}_{3}\right.$ ). ESI-MS: $m / z[\mathrm{M}+\mathrm{H}]^{+} 473$.

Diethyl 3-(6-Methyl-4-oxo-4H-chromen-3-yl)-1-phenyl -1H-pyrazole-4,5-dicarboxylate $(5 \mathrm{~g})$

Colourless solid. Yield $61 \%$. M.p. $131-133^{\circ} \mathrm{C}$. FT-IR $(\mathrm{KBr}): v$ 2923, 2852, 1721, 1656, 1547, 1462, 1245, 1009 $\mathrm{cm}^{-1} .{ }^{1} \mathrm{H}$ NMR $\left(300 \mathrm{MHz}, \mathrm{CDCl}_{3}\right): \delta 8.20(\mathrm{~s}, 1 \mathrm{H}, \mathrm{Ar}-\mathrm{H})$, 8.06 (s, 1H, Ar-H), 7.53-7.42 (m, 6H, Ar-H), 7.38 (d, 1H, J $=8.6 \mathrm{~Hz}, \operatorname{Ar}-\mathrm{H}), 4.29\left(\mathrm{q}, 2 \mathrm{H}, J=6.8 \mathrm{~Hz}, \mathrm{OCH}_{2}\right), 4.24(\mathrm{q}$, $\left.2 \mathrm{H}, J=6.8 \mathrm{~Hz}, \mathrm{OCH}_{2}\right), 1.25\left(\mathrm{t}, 3 \mathrm{H}, J=6.8 \mathrm{~Hz}, \mathrm{CH}_{3}\right), 1.21$ $\left(\mathrm{t}, 3 \mathrm{H}, J=6.8 \mathrm{~Hz}, \mathrm{CH}_{3}\right), 2.50\left(\mathrm{~s}, 3 \mathrm{H}, \mathrm{CH}_{3}\right) .{ }^{13} \mathrm{C} \mathrm{NMR}(75$ $\left.\mathrm{MHz}, \mathrm{CDCl}_{3}\right): \delta 175.1 .161 .9,160.0,154.2,144.5,139.0$, $137.0,135.4,129.1,125.6,124.5,117.8,62.3,60.8,20.9$, 14.0, 13.7. ESI-MS: $m / z[\mathrm{M}+\mathrm{H}]^{+} 447$.

Dimethyl 3-(6-Methyl-4-oxo-4H-chromen-3-yl)-1-mtolyl-1H-pyrazole-4,5-dicarboxylate (5h)

Colourless solid. Yield $82 \%$. M.p. $168-170{ }^{\circ} \mathrm{C}$. FT-IR (KBr): $v 2925,2534,1735,1655,1485,1233,1156 \mathrm{~cm}^{-1} .{ }^{1} \mathrm{H}$ NMR (300 MHz, $\left.\mathrm{CDCl}_{3}\right): \delta 8.22(\mathrm{~s}, 1 \mathrm{H}, \mathrm{Ar}-\mathrm{H}), 8.09(\mathrm{~d}, 1 \mathrm{H}$, $J=1.6 \mathrm{~Hz}, \mathrm{Ar}-\mathrm{H}), 7.46\left(\mathrm{dd}, 1 \mathrm{H}, J_{1}=8.3 \mathrm{~Hz}, J_{2}=6.0 \mathrm{~Hz}, \mathrm{Ar}-\right.$ H), 7.40-7.30 (m, 3H, Ar-H), 7.28-7.20 (m, 2H, Ar-H), 3.86 $\left(\mathrm{s}, 3 \mathrm{H}, \mathrm{OCH}_{3}\right), 3.76\left(\mathrm{~s}, 3 \mathrm{H}, \mathrm{OCH}_{3}\right), 2.52\left(\mathrm{~s}, 3 \mathrm{H}, \mathrm{CH}_{3}\right), 2.46(\mathrm{~s}$, $\left.3 \mathrm{H}, \mathrm{CH}_{3}\right) .{ }^{13} \mathrm{C}$ NMR $\left(75 \mathrm{MHz}, \mathrm{CDCl}_{3}\right): \delta 174.3,160.4,154.2$, $139.4,135.3,134.9,129.8,128.9,125.7,125.1,123.9,121.3$, 117.9, 53.0, 52.0, 21.3, 21.0. ESI-MS: $m / z[\mathrm{M}+\mathrm{H}]^{+} 433$.

Dimethyl 1-(4-Methoxyphenyl)-3-(6-methyl-4-oxo-4Hchromen-3-yl)-1 $H$-pyrazole-4,5-dicarboxylate (5i)

Colourless solid. Yield $62 \%$. M.p. $179-181^{\circ} \mathrm{C}$. FT-IR (KBr): $v 2923,1732,1656,1222,1148,772 \mathrm{~cm}^{-1} .{ }^{1} \mathrm{H}$ NMR $\left(300 \mathrm{MHz}, \mathrm{CDCl}_{3}\right): \delta 8.22(\mathrm{~s}, 1 \mathrm{H}, \mathrm{Ar}-\mathrm{H}), 8.06(\mathrm{~s}, 1 \mathrm{H}$, Ar-H), $7.46(\mathrm{~d}, 1 \mathrm{H}, J=8.4,6.4 \mathrm{~Hz}, \mathrm{Ar}-\mathrm{H}), 7.42-7.36(\mathrm{~m}$, $3 \mathrm{H}, \mathrm{Ar}-\mathrm{H}), 6.94$ (d, $2 \mathrm{H}, J=8.6 \mathrm{~Hz}, \mathrm{Ar}-\mathrm{H}), 3.86(\mathrm{~s}, 3 \mathrm{H}$, $\left.\mathrm{OCH}_{3}\right), 3.84\left(\mathrm{~s}, 3 \mathrm{H}, \mathrm{OCH}_{3}\right), 3.76\left(\mathrm{~s}, 3 \mathrm{H}, \mathrm{OCH}_{3}\right), 2.50(\mathrm{~s}$, $\left.3 \mathrm{H}, \mathrm{CH}_{3}\right)$. ESI-MS: $m / z[\mathrm{M}+\mathrm{H}]^{+} 449$.

Dimethyl 1-(2-Fluorophenyl)-3-(6-methyl-4-oxo-4Hchromen-3-yl)-1H-pyrazole-4,5-dicarboxylate (5j)

Colourless solid. Yield 71\%. M.p. $170-172{ }^{\circ} \mathrm{C}$. FT-IR (KBr): $v$ 2924, 2856, 1740, 1648, 1467, 1240, 1190, 1088 
$\mathrm{cm}^{-1} .{ }^{1} \mathrm{H}$ NMR $\left(300 \mathrm{MHz}, \mathrm{CDCl}_{3}\right): \delta 8.28(\mathrm{~s}, 1 \mathrm{H}, \mathrm{Ar}-\mathrm{H})$, $8.06(\mathrm{~s}, 1 \mathrm{H}, \mathrm{Ar}-\mathrm{H}), 7.58(\mathrm{t}, 1 \mathrm{H}, J=1.7 \mathrm{~Hz}, \mathrm{Ar}-\mathrm{H}), 7.50-7.17$ $(\mathrm{m}, 5 \mathrm{H}, \mathrm{Ar}-\mathrm{H}), 3.84\left(\mathrm{~s}, 3 \mathrm{H}, \mathrm{OCH}_{3}\right), 3.82\left(\mathrm{~s}, 3 \mathrm{H}, \mathrm{OCH}_{3}\right)$, $2.50\left(\mathrm{~s}, 3 \mathrm{H}, \mathrm{CH}_{3}\right) .{ }^{13} \mathrm{C} \mathrm{NMR}\left(75 \mathrm{MHz}, \mathrm{CDCl}_{3}\right): \delta 175.0$, 154.4, 135.1, 130.8, 128.0, 125.5, 124.6, 123.7, 117.9, 116.1, 52.8, 52.3, 29.6. ESI-MS: $m / z[\mathrm{M}+\mathrm{H}]^{+} 437,[\mathrm{M}+\mathrm{Na}]^{+} 459$.

Dimethyl 1-(4-Bromophenyl)-3-(6-methyl-4-oxo-4Hchromen-3-yl)-1H-pyrazole-4,5-dicarboxylate (5k)

Brownish solid. Yield $67 \%$. M.p. $145-147{ }^{\circ} \mathrm{C} .{ }^{1} \mathrm{H}$ NMR $\left(300 \mathrm{MHz}, \mathrm{CDCl}_{3}\right): \delta 8.20$ (s, $1 \mathrm{H}$, imine), $8.06(\mathrm{~s}, 1 \mathrm{H}$, $\mathrm{Ar}-\mathrm{H}), 7.61(\mathrm{~d}, 2 \mathrm{H}, J=9.0 \mathrm{~Hz}, \mathrm{Ar}-\mathrm{H}), 7.48\left(\mathrm{dd}, 1 \mathrm{H}, J_{1}=9.0\right.$ $\left.\mathrm{Hz}, J_{2}=6.8 \mathrm{~Hz}, \mathrm{Ar}-\mathrm{H}\right), 7.40(\mathrm{~d}, 2 \mathrm{H}, J=2.2 \mathrm{~Hz}, \mathrm{Ar}-\mathrm{H}), 7.38-$ $7.36(\mathrm{~m}, 1 \mathrm{H}, \mathrm{Ar}-\mathrm{H}), 3.86\left(\mathrm{~s}, 3 \mathrm{H}, \mathrm{OCH}_{3}\right), 3.78(\mathrm{~s}, 3 \mathrm{H}$, $\left.\mathrm{OCH}_{3}\right), 2.50\left(\mathrm{~s}, 3 \mathrm{H}, \mathrm{CH}_{3}\right)$. ESI-MS: $m / z[\mathrm{M}+\mathrm{H}]^{+} 497$.

Dimethyl 3-(6-Chloro-4-oxo-4H-chromen-3-yl)-1-phenyl-1H-pyrazole-4,5-dicarboxylate (5l)

Colourless solid. Yield 77\%. M.p. $152-154^{\circ} \mathrm{C}$. FT-IR (KBr): $v 2924,2856,1728,1659,1454,1239,1036 \mathrm{~cm}^{-1} .{ }^{1} \mathrm{H}$ NMR (300 MHz, $\left.\mathrm{CDCl}_{3}\right): \delta 8.23(\mathrm{~s}, 1 \mathrm{H}, \mathrm{Ar}-\mathrm{H}), 8.09(\mathrm{~s}, 1 \mathrm{H}$, Ar-H), 7.53-7.45 (m, 6H, Ar-H), 7.40 (d, $1 \mathrm{H}, J=8.6 \mathrm{~Hz}$, Ar-H), 3.85 (s, 3H, $\left.\mathrm{OCH}_{3}\right), 3.79\left(\mathrm{~s}, 3 \mathrm{H}, \mathrm{OCH}_{3}\right) \cdot{ }^{13} \mathrm{C} \mathrm{NMR}$ $\left(75 \mathrm{MHz}, \mathrm{CDCl}_{3}\right): \delta 175.2,160.3,157.3,154.2,144.4$, 139.0, 136.5, 129.1, 129.0, 126.3, 124.4, 120.7, 119.0, 116.6, 107.0, 100.0, 53.0, 51.9. ESI-MS: $m / z[\mathrm{M}+\mathrm{H}]^{+} 439$.

Dimethyl 3-(6-Chloro-4-oxo-4H-chromen-3-yl)-1-mtolyl-1H-pyrazole-4,5-dicarboxylate $(5 \mathrm{~m})$

Pale brownish solid. Yield $61 \%$. M.p. $154-156{ }^{\circ} \mathrm{C} .{ }^{1} \mathrm{H}$ NMR $\left(300 \mathrm{MHz}, \mathrm{CDCl}_{3}\right): \delta 8.24(\mathrm{~d}, 1 \mathrm{H}, J=2.4, \mathrm{Ar}-\mathrm{H})$, $8.22\left(\mathrm{~s}, 1 \mathrm{H}\right.$, imine), $7.63\left(\mathrm{dd}, 1 \mathrm{H}, J_{1}=9.0 \mathrm{~Hz}, J_{2}=6.8 \mathrm{~Hz}\right.$, Ar-H), $7.46(\mathrm{~d}, 1 \mathrm{H}, J=9.0 \mathrm{~Hz}, \mathrm{Ar}-\mathrm{H}), 7.36-7.30(\mathrm{~m}, 2 \mathrm{H}$, Ar-H), 7.24-7.18 (m, 2H, Ar-H), 3.84 (s, 3H, $\left.\mathrm{OCH}_{3}\right), 3.80$ $\left(\mathrm{s}, 3 \mathrm{H}, \mathrm{OCH}_{3}\right), 2.45\left(\mathrm{~s}, 3 \mathrm{H}, \mathrm{CH}_{3}\right)$.

Dimethyl 3-(6-Chloro-4-oxo-4H-chromen-3-yl)-1-(4methoxyphenyl)-1H-pyrazole-4,5-dicarboxylate (5n)

Pale yellow solid. Yield $72 \%$. M.p. $158-160^{\circ} \mathrm{C}$. FT-IR (KBr): $v 2925,1736,1653,1250,1105,763 \mathrm{~cm}^{-1} .{ }^{1} \mathrm{H}$ NMR $\left(300 \mathrm{MHz}, \mathrm{CDCl}_{3}\right): \delta 8.24(\mathrm{~d}, 1 \mathrm{H}, J=2.4 \mathrm{~Hz}, \mathrm{Ar}-\mathrm{H}), 8.20$ $(\mathrm{s}, 1 \mathrm{H}, \mathrm{Ar}-\mathrm{H}), 7.60\left(\mathrm{dd}, 1 \mathrm{H}, J_{1}=9.0 \mathrm{~Hz}, J_{2}=6.8 \mathrm{~Hz}, \mathrm{Ar}-\mathrm{H}\right)$, $7.44(\mathrm{~d}, 1 \mathrm{H}, J=9.0 \mathrm{~Hz}, \operatorname{Ar}-\mathrm{H}), 7.40(\mathrm{~d}, 2 \mathrm{H}, J=9.0 \mathrm{~Hz}$, $\mathrm{Ar}-\mathrm{H}), 6.94(\mathrm{~d}, 2 \mathrm{H}, J=9.0 \mathrm{~Hz}, \mathrm{Ar}-\mathrm{H}), 3.86\left(\mathrm{~s}, 3 \mathrm{H}, \mathrm{OCH}_{3}\right)$, $3.84\left(\mathrm{~s}, 3 \mathrm{H}, \mathrm{OCH}_{3}\right), 3.78\left(\mathrm{~s}, 3 \mathrm{H}, \mathrm{OCH}_{3}\right)$. ESI-MS: $m / z$ $[\mathrm{M}+\mathrm{H}]^{+} 469$.

Dimethyl 3-(6-Bromo-4-oxo-4H-chromen-3-yl)-1-phenyl-1 $H$-pyrazole-4,5-dicarboxylate (5o)

Colourless solid. Yield $46 \%$. M.p. $169-171^{\circ} \mathrm{C}$. FT-IR $(\mathrm{KBr}):$ v 2924, 1728, 1659, 1454, 1384, 1239, 1036, 758 $\mathrm{cm}^{-1} .{ }^{1} \mathrm{H}$ NMR $\left(300 \mathrm{MHz}, \mathrm{CDCl}_{3}\right): \delta 8.41(\mathrm{~d}, 1 \mathrm{H}, J=2.2$ $\mathrm{Hz}, \mathrm{Ar}-\mathrm{H}), 8.24(\mathrm{~s}, 1 \mathrm{H}, \mathrm{Ar}-\mathrm{H}), 7.76\left(\mathrm{dd}, 1 \mathrm{H}, J_{1}=7.6 \mathrm{~Hz}, J_{2}\right.$ $=6.0 \mathrm{~Hz}, \mathrm{Ar}-\mathrm{H}), 7.50-7.44(\mathrm{~m}, 5 \mathrm{H}, \mathrm{Ar}-\mathrm{H}), 7.39(\mathrm{~d}, 1 \mathrm{H}, \mathrm{J}=$ $7.6 \mathrm{~Hz}, \mathrm{Ar}-\mathrm{H}), 3.85\left(\mathrm{~s}, 3 \mathrm{H}, \mathrm{OCH}_{3}\right), 3.79\left(\mathrm{~s}, 3 \mathrm{H}, \mathrm{OCH}_{3}\right) .{ }^{13} \mathrm{C}$ $\operatorname{NMR}\left(75 \mathrm{MHz}, \mathrm{CDCl}_{3}\right): \delta 173.8,172.4,159.2,155.0,154.5$,
$138.9,136.8,132.3,129.3,128.9,125.8,124.4,120.1,119.0$, 111.5, 108.1, 53.2, 52.1. ESI-MS: $m / z[\mathrm{M}+\mathrm{H}]^{+} 483$.

Dimethyl 3-(6-Bromo-4-oxo-4H-chromen-3-yl)-1-mtolyl-1 $H$-pyrazole-4,5-dicarboxylate $(5 \mathrm{p})$

Colourless solid. Yield $74 \%$. M.p. $151-153^{\circ} \mathrm{C}$. FT-IR $(\mathrm{KBr}): v 2925,1724,1655,1493,1328,1233,1155,1070$ $\mathrm{cm}^{-1} .{ }^{1} \mathrm{H}$ NMR $\left(300 \mathrm{MHz}, \mathrm{CDCl}_{3}\right): \delta 8.40(\mathrm{~d}, 1 \mathrm{H}, J=2.4$ $\mathrm{Hz}, \mathrm{Ar}-\mathrm{H}), 8.20$ (s, 1H, imine), $7.76\left(\mathrm{dd}, 1 \mathrm{H}, J_{1}=8.4 \mathrm{~Hz}, J_{2}\right.$ $=6.4 \mathrm{~Hz}, \mathrm{Ar}-\mathrm{H}), 7.40-7.30(\mathrm{~m}, 3 \mathrm{H}, \mathrm{Ar}-\mathrm{H}), 7.23-7.14(\mathrm{~m}$, $1 \mathrm{H}, \mathrm{Ar}-\mathrm{H}), 3.84\left(\mathrm{~s}, 3 \mathrm{H}, \mathrm{OCH}_{3}\right), 3.78\left(\mathrm{~s}, 3 \mathrm{H}, \mathrm{OCH}_{3}\right), 2.58(\mathrm{~s}$, $\left.3 \mathrm{H}, \mathrm{CH}_{3}\right) .{ }^{13} \mathrm{C}$ NMR $\left(75 \mathrm{MHz}, \mathrm{CDCl}_{3}\right): \delta 174.5,162.2$, $160.2,158.1,150.7,144.1,139.2,136.4,129.7,124.9,121.1$, $119.6,118.3,117.0,110.2,104.1,52.9,51.8,21.2$. ESI-MS: $m / z[\mathrm{M}+\mathrm{H}]^{+} 497,[\mathrm{M}+2]^{+} 499$.

Dimethyl 3-(6-Bromo-4-oxo-4H-chromen-3-yl)-1-(4methoxyphenyl)-1 $\mathrm{H}$-pyrazole-4,5-dicarboxylate (5q)

Pale yellow solid. Yield $68 \%$. M.p. $164-166{ }^{\circ} \mathrm{C} .{ }^{1} \mathrm{H}$ $\operatorname{NMR}\left(300 \mathrm{MHz}, \mathrm{CDCl}_{3}\right): \delta 8.40\left(\mathrm{dd}, 1 \mathrm{H}, J_{1}=9.0 \mathrm{~Hz}, J_{2}=\right.$ $2.2 \mathrm{~Hz}, \mathrm{Ar}-\mathrm{H}), 8.20(\mathrm{~s}, 1 \mathrm{H}, \mathrm{Ar}-\mathrm{H}), 7.76\left(\mathrm{dd}, 1 \mathrm{H}, J_{1}=9.0 \mathrm{~Hz}\right.$, $\left.J_{2}=6.8 \mathrm{~Hz}, \mathrm{Ar}-\mathrm{H}\right), 7.40-7.33(\mathrm{~m}, 3 \mathrm{H}, \mathrm{Ar}-\mathrm{H}), 6.94(\mathrm{~d}, 2 \mathrm{H}, J$ $=9.0 \mathrm{~Hz}, \mathrm{Ar}-\mathrm{H}), 3.86\left(\mathrm{~s}, 3 \mathrm{H}, \mathrm{OCH}_{3}\right), 3.84\left(\mathrm{~s}, 3 \mathrm{H}, \mathrm{OCH}_{3}\right)$, $3.78\left(\mathrm{~s}, 3 \mathrm{H}, \mathrm{OCH}_{3}\right) .{ }^{13} \mathrm{C} \mathrm{NMR}\left(75 \mathrm{MHz}, \mathrm{CDCl}_{3}\right): \delta 174.4$, $162.1,159.9,154.1,144.4,136.1,133.6,132.7,126.6,126.0$, 125.4, 124.4, 118.1, 117.8, 117.4, 53.0, 52.0.

Diethyl 3-(4-Oxo-4H-chromen-3-yl)-1-phenyl- $1 H$-pyrazole-4,5-dicarboxylate $(5$ r)

Pale yellow solid. Yield $61 \%$. M.p. $119-121{ }^{\circ} \mathrm{C} .{ }^{1} \mathrm{H}$ $\operatorname{NMR}\left(300 \mathrm{MHz}, \mathrm{CDCl}_{3}\right): \delta 8.30\left(\mathrm{dd}, 1 \mathrm{H}, J_{1}=7.8 \mathrm{~Hz}, J_{2}=\right.$ $6.4 \mathrm{~Hz}, \mathrm{Ar}-\mathrm{H}), 8.22(\mathrm{~s}, 1 \mathrm{H}, \mathrm{Ar}-\mathrm{H}), 7.68(\mathrm{t}, 1 \mathrm{H}, J=2.5 \mathrm{~Hz}$, Ar-H), 7.52-7.39 (m, 7H, Ar-H), 4.30 (q, $2 \mathrm{H}, J=7.1 \mathrm{~Hz}$, $\left.\mathrm{OCH}_{2}\right), 4.24\left(\mathrm{q}, 2 \mathrm{H}, J=3.5 \mathrm{~Hz}, \mathrm{OCH}_{2}\right), 1.24(\mathrm{t}, 3 \mathrm{H}, J=4.3$ $\left.\mathrm{Hz}, \mathrm{CH}_{3}\right), 1.10\left(\mathrm{t}, 3 \mathrm{H}, J=3.2 \mathrm{~Hz}, \mathrm{CH}_{3}\right) .{ }^{13} \mathrm{C}$ NMR $(300$ $\left.\mathrm{MHz}, \mathrm{CDCl}_{3}\right): \delta 174.9,161.8,159.9,156.3,154.2,144.3$, $139.0,133.6,126.4,125.4,124.4,118.1,62.3,60.7,13.9$, 13.7. ESI-MS: $m / z[\mathrm{M}+\mathrm{H}]^{+} 433,[\mathrm{M}+\mathrm{Na}]^{+} 455$.

Dimethyl 3-(5-Oxo-5H-furo[3,2-g]chromen-6-yl)-1phenyl-1 $H$-pyrazole-4,5-dicarboxylate (5s)

Brown solid. Yield $77 \%$. M.p. $176-178{ }^{\circ} \mathrm{C}$. FT-IR (KBr): $v 2953,1733,1651,1457,1162 \mathrm{~cm}^{-1} .{ }^{1} \mathrm{H}$ NMR $(300$ $\left.\mathrm{MHz}, \mathrm{CDCl}_{3}\right): \delta 8.52(\mathrm{~s}, 1 \mathrm{H}, \mathrm{Ar}-\mathrm{H}), 8.26(\mathrm{~s}, 1 \mathrm{H}, \mathrm{Ar}-\mathrm{H})$, $7.72(\mathrm{~d}, 1 \mathrm{H}, J=1.6 \mathrm{~Hz}, \mathrm{Ar}-\mathrm{H}), 7.57(\mathrm{~s}, 1 \mathrm{H}, \mathrm{Ar}-\mathrm{H}), 7.52-$ $7.41(\mathrm{~m}, 5 \mathrm{H}, \mathrm{Ar}-\mathrm{H}), 6.90(\mathrm{~d}, 1 \mathrm{H}, J=1.6 \mathrm{~Hz}, \mathrm{Ar}-\mathrm{H}), 3.84(\mathrm{~s}$, $\left.3 \mathrm{H}, \mathrm{OCH}_{3}\right), 3.76\left(\mathrm{~s}, 3 \mathrm{H}, \mathrm{OCH}_{3}\right) .{ }^{13} \mathrm{C} \mathrm{NMR}(75 \mathrm{MHz}$, $\left.\mathrm{CDCl}_{3}\right): \delta 175.2,157.3,154.5,147.5,144.4,139.0,129.3$, 126.3, 124.4, 120.7, 119.0, 116.6, 107.0, 53.0, 51.9. ESI-MS: $\mathrm{m} / z[\mathrm{M}+\mathrm{H}]^{+} 445$.

Dimethyl 3-(5-Oxo-5H-furo[3,2-g]chromen-6-yl)-1-mtolyl-1H-pyrazole-4,5-dicarboxylate $(5 t)$

Colourless solid. Yield 68\%. M.p. $192-194^{\circ} \mathrm{C}$. FT-IR (KBr): $v 2949,1721,1650,1589,1460,1165,1037 \mathrm{~cm}^{-1} .{ }^{1} \mathrm{H}$ NMR $\left(300 \mathrm{MHz}, \mathrm{CDCl}_{3}\right): \delta 8.52(\mathrm{~s}, 1 \mathrm{H}, \mathrm{Ar}-\mathrm{H}), 8.26(\mathrm{~s}, 1 \mathrm{H}$, 
Ar-H), 7.72 (s, 1H, Ar-H), 7.58 (s, 1H, Ar-H), 7.36-7.20 (m, 4H, Ar-H), 6.90 (s, 1H, Ar-H), 3.86 (s, 3H, $\left.\mathrm{OCH}_{3}\right)$, $3.76\left(\mathrm{~s}, 3 \mathrm{H}, \mathrm{OCH}_{3}\right), 2.44\left(\mathrm{~s}, 3 \mathrm{H}, \mathrm{CH}_{3}\right) .{ }^{13} \mathrm{C} \mathrm{NMR}(75 \mathrm{MHz}$, $\left.\mathrm{CDCl}_{3}\right): \delta 162.6,160.6,154.6,154.2,147.7,144.4,139.6$, 138.8, 136.7, 129.9, 128.9, 126.4, 125.0, 121.2, 118.9, 107.0, 53.1, 52.0, 29.3. ESI-MS: $m / z[\mathrm{M}+\mathrm{H}]^{+} 459$.

Diethyl 3-(5-Oxo-5H-furo[3,2-g]chromen-6-yl)-1-phenyl-1 $H$-pyrazole-4,5-dicarboxylate $(5 \mathrm{u})$

Brown solid. Yield 64\%. M.p. $162-164{ }^{\circ} \mathrm{C}$. FT-IR $(\mathrm{KBr}): v$ 2949, 1721, 1650, 1589, 1460, 1165, 1037, 795 $\mathrm{cm}^{-1} .{ }^{1} \mathrm{H}$ NMR $\left(300 \mathrm{MHz}, \mathrm{CDCl}_{3}\right): \delta 8.50$ (s, $\left.1 \mathrm{H}, \mathrm{Ar}-\mathrm{H}\right)$, 8.22 (s, 1H, Ar-H), 7.70 (d, 1H, J = 2.2 Hz, Ar-H), 7.587.39 (m, 5H, Ar-H), 6.90 (s, 1H, Ar-H), 4.29 (q, 2H, J = $\left.7.5 \mathrm{~Hz}, \mathrm{OCH}_{2}\right), 4.23\left(\mathrm{q}, 2 \mathrm{H}, J=4.5 \mathrm{~Hz}, \mathrm{OCH}_{2}\right), 1.23(\mathrm{t}$, $\left.3 \mathrm{H}, J=6.7 \mathrm{~Hz}, \mathrm{CH}_{3}\right), 1.19\left(\mathrm{t}, 3 \mathrm{H}, J=5.2 \mathrm{~Hz}, \mathrm{CH}_{3}\right) \cdot{ }^{13} \mathrm{C}$ NMR (75 MHz, $\left.\mathrm{CDCl}_{3}\right): \delta 174.6,161.4,159.5,153.9$, $147.1,138.9,128.7,125.9,124.1,120.5,118.8,116.7$, 106.7, 99.7, 95.8, 61.8, 60.3, 13.8. ESI-MS: $m / z[\mathrm{M}+\mathrm{H}]^{+}$, $473[\mathrm{M}+\mathrm{Na}]^{+} 495$.

Dimethyl 3-(4-Oxo-4H-furo[2,3-h]chromen-3-yl)-1phenyl-1 $H$-pyrazole-4,5-dicarboxylate $(5 \mathrm{v})$

Colourless solid. Yield 79\%. M.p. $173-175^{\circ} \mathrm{C}$. FT-IR $(\mathrm{KBr}):$ v 2953, 1733, 1651, 1588, 1457, 1269, 1039, 758 $\mathrm{cm}^{-1} .{ }^{1} \mathrm{H}$ NMR $\left(300 \mathrm{MHz}, \mathrm{CDCl}_{3}\right): \delta 8.30$ (s, $\left.1 \mathrm{H}, \mathrm{Ar}-\mathrm{H}\right)$, $8.21(\mathrm{~d}, 1 \mathrm{H}, J=8.6 \mathrm{~Hz}, \mathrm{Ar}-\mathrm{H}), 7.74$ (s, 1H, Ar-H), 7.587.42 (m, 6H, Ar-H), 7.12 (s, 1H, Ar-H), 3.86 (s, 3H, $\left.\mathrm{OCH}_{3}\right)$, $3.78\left(\mathrm{~s}, 3 \mathrm{H}, \mathrm{OCH}_{3}\right) .{ }^{13} \mathrm{C} \mathrm{NMR}\left(75 \mathrm{MHz}, \mathrm{CDCl}_{3}\right): \delta 174.6$, $162.3,160.3,158.2,153.3,150.8,145.7,144.2,139.0,136.4$, $129.1,128.9,125.7,124.4,122.4,119.6,118.3,116.7,110.4$, 104.2, 53.0, 51.9. ESI-MS: $m / z[\mathrm{M}+\mathrm{H}]^{+} 445$.

Dimethyl 3-(4-Oxo-4H-furo[2,3-h]chromen-3-yl)-1-mtolyl-1H-pyrazole-4,5-dicarboxylate (5w)

Pale yellow solid. Yield 82\%. M.p. $189-191{ }^{\circ} \mathrm{C}$. FT-IR (KBr): $v$ 2952, 1732, 1652, 1588, 1456, 1234, 1039, $763 \mathrm{~cm}^{-1} .{ }^{1} \mathrm{H}$ NMR $\left(300 \mathrm{MHz}, \mathrm{CDCl}_{3}\right): \delta 8.28(\mathrm{~s}, 1 \mathrm{H}$, Ar-H), 8.18 (dd, $\left.1 \mathrm{H}, J_{1}=8.4 \mathrm{~Hz}, J_{2}=6.4 \mathrm{~Hz}, \mathrm{Ar}-\mathrm{H}\right), 7.72$ (s, 1H, Ar-H), 7.52 (d, 1H, J = 8.6 Hz, Ar-H), 7.36-7.18 (m, 4H, Ar-H), 7.08 (s, 1H, Ar-H), 3.84 (s, 3H, $\mathrm{OCH}_{3}$ ), $3.76\left(\mathrm{~s}, 3 \mathrm{H}, \mathrm{OCH}_{3}\right), 2.42\left(\mathrm{~s}, 3 \mathrm{H}, \mathrm{CH}_{3}\right) .{ }^{13} \mathrm{C} \mathrm{NMR}(75 \mathrm{MHz}$, $\left.\mathrm{CDCl}_{3}\right): \delta 174.5,162.2,160.2,158.1,153.2,150.7,145.6$, $144.1,139.2,136.4,129.7,128.8,124.9,122.3,121.1$, $119.6,118.3,117.0,110.2,104.1,52.9,51.8,21.2$. ESI-MS: $m / z[\mathrm{M}+\mathrm{H}]^{+} 459$.

Diethyl 3-(4-Oxo-4H-furo[2,3-h]chromen-3-yl)-1-phenyl-1H-pyrazole-4,5-dicarboxylate $(\mathbf{5 x})$

Colourless solid. Yield 78\%. M.p. $167-169^{\circ} \mathrm{C}$. FT-IR (KBr): $v$ 2926, 1731, 1657, 1464, 1221, $762 \mathrm{~cm}^{-1} .{ }^{1} \mathrm{H}$ NMR $\left(300 \mathrm{MHz}, \mathrm{CDCl}_{3}\right): \delta 8.26(\mathrm{~s}, 1 \mathrm{H}, \mathrm{Ar}-\mathrm{H}), 8.20(\mathrm{~d}, 1 \mathrm{H}, J=$ $8.3 \mathrm{~Hz}, \mathrm{Ar}-\mathrm{H}), 7.73$ (d, $1 \mathrm{H}, J=2.2 \mathrm{~Hz}, \mathrm{Ar}-\mathrm{H}), 7.58-7.42$ (m, 6H, Ar-H), 7.10 (s, 1H, Ar-H), 4.29 (q, 2H, J=6.7 Hz, $\left.\mathrm{OCH}_{2}\right), 4.23\left(\mathrm{q}, 2 \mathrm{H}, J=4.5 \mathrm{~Hz}, \mathrm{OCH}_{2}\right), 1.24(\mathrm{t}, 3 \mathrm{H}, J=4.5$ $\left.\mathrm{Hz}, \mathrm{CH}_{3}\right), 1.19\left(\mathrm{t}, 3 \mathrm{H}, J=6.5 \mathrm{~Hz}, \mathrm{CH}_{3}\right) .{ }^{13} \mathrm{C} \mathrm{NMR}(75 \mathrm{MHz}$,
$\left.\mathrm{CDCl}_{3}\right): \delta 174.8,161.8,159.9,158.1,153.3,150.7,145.7$, $144.3,138.9,137.1,129.1,124.4,119.6,118.4,117.0,110.3$, 104.1, 62.3, 60.7, 13.8, 13.9. ESI-MS: $m / z[\mathrm{M}+\mathrm{H}]^{+} 473$.

\section{4. General Procedure for the Preparation of Pyrazolylmethanones 6a-u}

$\mathrm{K}_{2} \mathrm{CO}_{3}(0.276 \mathrm{~g}, 2 \mathrm{mmol})$ was added to a stirred solution of $(E)$-3-((2-phenylhydrazono)methyl)-4H-chromen4-one $3 \mathrm{a}(0.264 \mathrm{~g}, 1 \mathrm{mmol})$ in acetonitrile $(3 \mathrm{~mL})$ at room temperature. The reaction mixture was refluxed for $12 \mathrm{~h}$ and after completion of the reaction (TLC), the solvent was removed under reduced pressure. The crude product was purified by column chromatography using silica gel (60-120, hexane-ethyl acetate, 97:3) affording 6a. Similarly, the compounds $\mathbf{6 b}-\mathbf{u}$ were prepared by treating the (E)-3-((2-phenylhydrazono)methyl)-4H-chromen-4-ones 3a-h, 3k-s, 3u-v with $\mathrm{K}_{2} \mathrm{CO}_{3}$.

(2-Hydroxyphenyl)(1-phenyl-1H-pyrazol-4-yl)methanone (6a)

Pale yellow solid. Yield 88\%. M.p. $113-114^{\circ} \mathrm{C}$. FT-IR (KBr): $v 3129,1622,1589,1482,1293 \mathrm{~cm}^{-1} .{ }^{1} \mathrm{H}$ NMR $(300$ $\left.\mathrm{MHz}, \mathrm{CDCl}_{3}\right): \delta 12.02(\mathrm{~s}, 1 \mathrm{H}, \mathrm{ArOH}), 8.48(\mathrm{~s}, 1 \mathrm{H}$, pyrazole $\left.\mathrm{H}_{3}\right), 8.18\left(\mathrm{~s}, 1 \mathrm{H}\right.$, pyrazole $\left.\mathrm{H}_{5}\right), 7.92\left(\mathrm{dd}, 1 \mathrm{H}, J_{1}=7.9 \mathrm{~Hz}, J_{2}\right.$ $=1.1 \mathrm{~Hz}, \mathrm{Ar}-\mathrm{H}), 7.75$ (d, 2H, $J=7.7 \mathrm{~Hz}, \mathrm{Ar}-\mathrm{H}), 7.56-7.48$ (m, 3H, Ar-H), 7.39 (t, 1H, J = 7.3 Hz, Ar-H), 7.07 (d, 1H, $J=8.3 \mathrm{~Hz}, \mathrm{Ar}-\mathrm{H}), 6.97$ (t, $1 \mathrm{H}, J=7.9 \mathrm{~Hz}, \mathrm{Ar}-\mathrm{H}) .{ }^{13} \mathrm{C} \mathrm{NMR}$ $\left(75 \mathrm{MHz}, \mathrm{CDCl}_{3}\right): \delta 192.0,162.6,142.3,139.1,135.9$, 131.1, 130.4, 129.6, 127.8, 123.3, 120.0, 119.7, 119.0, 118.4 . ESI-MS: $m / z[\mathrm{M}+\mathrm{H}]^{+} 265$.

(2-Hydroxyphenyl)(1-m-tolyl-1H-pyrazol-4-yl)methanone $(6 b)$

Yellow thick liquid. Yield 76\%. FT-IR (KBr): v 3447, 1622, 1539, 1483, 1238, 903, $771 \mathrm{~cm}^{-1} .{ }^{1} \mathrm{H}$ NMR (300 MHz, $\left.\mathrm{CDCl}_{3}\right): \delta 11.95(\mathrm{~s}, 1 \mathrm{H}, \mathrm{ArOH}), 8.39\left(\mathrm{~s}, 1 \mathrm{H}\right.$, pyrazole $\left.\mathrm{H}_{3}\right)$, $8.09\left(\mathrm{~s}, 1 \mathrm{H}\right.$, pyrazole $\left.\mathrm{H}_{5}\right), 7.84\left(\mathrm{dd}, J_{1}=8.1 \mathrm{~Hz}, J_{2}=1.7 \mathrm{~Hz}\right.$, $1 \mathrm{H}$, Ar-H), $7.52-7.41(\mathrm{~m}, 3 \mathrm{H}), 7.30(\mathrm{t}, 1 \mathrm{H}, J=7.7 \mathrm{~Hz}$, Ar-H), 7.12 (d, 1H, J = 7.5 Hz, Ar-H), 6.99 (d, 1H, $J=8.4$ $\mathrm{Hz}, \mathrm{Ar}-\mathrm{H}), 6.89$ (t, $1 \mathrm{H}, J=7.1 \mathrm{~Hz}, \mathrm{Ar}-\mathrm{H}) .{ }^{13} \mathrm{C}$ NMR $(75$ $\left.\mathrm{MHz}, \mathrm{CDCl}_{3}\right): \delta 192.0,162.6,142.2,139.8,139.0,135.9$, $131.1,130.4,129.4,128.6,123.2,120.4,120.0,119.0,118.4$, 116.7, 21.4. ESI-MS: $m / z[\mathrm{M}+\mathrm{H}]^{+} 279$.

(2-Hydroxyphenyl)(1-(4-methoxyphenyl)-1H-pyrazol-4-yl)methanone $(6 \mathrm{c})$

Yellow thick liquid. Yield 73\%. FT-IR (KBr): $v$ 3422, 2924, 1722, 1590, 1237, $771 \mathrm{~cm}^{-1} .{ }^{1} \mathrm{H}$ NMR (300 MHz, $\left.\mathrm{CDCl}_{3}\right): \delta 12.04(\mathrm{~s}, 1 \mathrm{H}, \mathrm{ArOH}), 8.39\left(\mathrm{~s}, 1 \mathrm{H}\right.$, pyrazole $\left.\mathrm{H}_{3}\right)$, $8.15\left(\mathrm{~s}, 1 \mathrm{H}\right.$, pyrazole $\left.\mathrm{H}_{5}\right), 7.91\left(\mathrm{dd}, 1 \mathrm{H}, J_{1}=7.9 \mathrm{~Hz}, J_{2}=1.3\right.$ $\mathrm{Hz}, \mathrm{Ar}-\mathrm{H}), 7.64$ (d, 2H, J = 9.0 Hz, Ar-H), 7.52 (t, 1H, J = $6.9 \mathrm{~Hz}, \mathrm{Ar}-\mathrm{H}), 7.09-6.93(\mathrm{~m}, 4 \mathrm{H}, \mathrm{Ar}-\mathrm{H}), 3.86(\mathrm{~s}, 3 \mathrm{H}$, $\left.\mathrm{OCH}_{3}\right) .{ }^{13} \mathrm{C} \mathrm{NMR}\left(75 \mathrm{MHz}, \mathrm{CDCl}_{3}\right): \delta 192.0,162.5,159.1$, 142.0, 135.9, 132.6, 131.1, 130.3, 123.0, 121.3, 120.0, 118.9, 118.4, 114.6, 55.5. ESI-MS: $m / z[\mathrm{M}+\mathrm{H}]^{+} 295$. 
(1-(2-Fluorophenyl)-1H-pyrazol-4-yl)(2-hydroxyphenyl)methanone (6d)

Pale yellow solid. Yield $63 \%$. M.p. $150-152^{\circ} \mathrm{C}$. FT-IR (KBr): $v$ 3067, 1675, 1501, 1219, $765 \mathrm{~cm}^{-1} .{ }^{1} \mathrm{H}$ NMR $(300$ $\left.\mathrm{MHz}, \mathrm{CDCl}_{3}\right) \delta 10.02(\mathrm{~s}, 1 \mathrm{H}, \mathrm{ArOH}), 8.32(\mathrm{~s}, 1 \mathrm{H}$, pyrazole $\left.\mathrm{H}_{3}\right), 7.89\left(\mathrm{~d}, J=8.1 \mathrm{~Hz}, 1 \mathrm{H}\right.$, pyrazole $\left.\mathrm{H}_{5}\right), 7.66\left(\mathrm{dd}, 1 \mathrm{H}, J_{1}=\right.$ $\left.7.5 \mathrm{~Hz}, J_{2}=1.5 \mathrm{~Hz}, \mathrm{Ar}-\mathrm{H}\right), 7.54\left(\mathrm{td}, 1 \mathrm{H}, J_{1}=9.6 \mathrm{~Hz}, J_{2}=1.7\right.$ $\mathrm{Hz}, \mathrm{Ar}-\mathrm{H}), 7.44-7.30(\mathrm{~m}, 5 \mathrm{H}) .{ }^{13} \mathrm{C} \mathrm{NMR}\left(75 \mathrm{MHz}, \mathrm{CDCl}_{3}\right)$ : $\delta 184.4,158.7,152.2,143.7,142.2,132.7,132.1,131.5$, $129.5,126.2,125.9,124.9,124.1,121.7,121.6,120.1$. ESIMS: $m / z[\mathrm{M}+\mathrm{H}]^{+} 283$.

(1-(3-Fluorophenyl)-1H-pyrazol-4-yl)(2-hydroxyphenyl)methanone (6e)

Pale yellow solid. Yield $69 \%$. M.p. $104-106^{\circ} \mathrm{C}$. FT-IR (KBr): $v$ 3127, 1602, 1542, 1245, $757 \mathrm{~cm}^{-1} .{ }^{1} \mathrm{H}$ NMR $(300$ $\left.\mathrm{MHz}, \mathrm{CDCl}_{3}\right): \delta 11.98(\mathrm{~s}, 1 \mathrm{H}, \mathrm{ArOH}), 8.48(\mathrm{~s}, 1 \mathrm{H}$, pyrazole $\left.\mathrm{H}_{3}\right), 8.18\left(\mathrm{~s}, 1 \mathrm{H}\right.$, pyrazole $\left.\mathrm{H}_{5}\right), 7.90\left(\mathrm{dd}, J_{1}=8.3 \mathrm{~Hz}, J_{2}=1.5\right.$ $\mathrm{Hz}, 1 \mathrm{H}, \mathrm{Ar}-\mathrm{H}), 7.58-7.46(\mathrm{~m}, 4 \mathrm{H}, \mathrm{Ar}-\mathrm{H}), 7.14-7.06$ (m, $2 \mathrm{H}, \mathrm{Ar}-\mathrm{H}), 6.98\left(\mathrm{dt}, 1 \mathrm{H}, J_{1}=8.3 \mathrm{~Hz}, J_{2}=1.5 \mathrm{~Hz}, \mathrm{Ar}-\mathrm{H}\right) .{ }^{13} \mathrm{C}$ NMR $\left(75 \mathrm{MHz}, \mathrm{CDCl}_{3}\right): \delta 191.9,164.8,162.7,161.5,142.5$, 140.3, 136.1, 131.0, 130.4, 123.6, 119.9, 119.0, 118.5, 114.8, 114.5, 107.7, 107.4. ESI-MS: $m / z[\mathrm{M}+\mathrm{H}]^{+} 283$.

(1-(3-Chlorophenyl)-1H-pyrazol-4-yl)(2-hydroxyphenyl)methanone (6f)

Yellow solid. Yield 66\%. M.p. $94-96{ }^{\circ} \mathrm{C}$. FT-IR (KBr): v 3127, 1581, 1464, 1215, $752 \mathrm{~cm}^{-1} .{ }^{1} \mathrm{H}$ NMR $(300 \mathrm{MHz}$, $\left.\mathrm{CDCl}_{3}\right): \delta 11.97(\mathrm{~s}, 1 \mathrm{H}, \mathrm{ArOH}), 8.47\left(\mathrm{~s}, 1 \mathrm{H}\right.$, pyrazole $\left.\mathrm{H}_{3}\right)$, $8.18\left(\mathrm{~s}, 1 \mathrm{H}\right.$, pyrazole $\left.\mathrm{H}_{5}\right), 7.89\left(\mathrm{dd}, J_{1}=7.9 \mathrm{~Hz}, J_{2}=1.5 \mathrm{~Hz}\right.$, $1 \mathrm{H}, \mathrm{Ar}-\mathrm{H}), 7.64(\mathrm{dd}, J=3.0 \mathrm{~Hz}, 1 \mathrm{H}, \mathrm{Ar}-\mathrm{H}), 7.53\left(\mathrm{dt}, 1 \mathrm{H}, J_{1}\right.$ $\left.=8.4 \mathrm{~Hz}, J_{2}=1.5 \mathrm{~Hz}, \mathrm{Ar}-\mathrm{H}\right), 7.44(\mathrm{t}, 1 \mathrm{H}, J=8.1 \mathrm{~Hz}, \mathrm{Ar}-\mathrm{H})$, $7.36(\mathrm{~d}, J=7.9 \mathrm{~Hz}, 1 \mathrm{H}, \operatorname{Ar}-\mathrm{H}), 7.07(\mathrm{~d}, 1 \mathrm{H}, J=7.5 \mathrm{~Hz}$, Ar-H), $6.98\left(\mathrm{dt}, 1 \mathrm{H}, J_{1}=8.1 \mathrm{~Hz}, J_{2}=1.0 \mathrm{~Hz}, \mathrm{Ar}-\mathrm{H}\right) .{ }^{13} \mathrm{C}$ NMR $\left(75 \mathrm{MHz}, \mathrm{CDCl}_{3}\right): \delta 191.8,162.6,142.5,140.0,136.1$, 135.5, 131.0, 130.6, 127.8, 123.6, 120.0, 119.1, 118.5, 117.5 . ESI-MS: $m / z[\mathrm{M}+\mathrm{H}]^{+} 299$.

(1-(4-Fluorophenyl)-1H-pyrazol-4-yl)(2-hydroxyphenyl)methanone $(6 \mathrm{~g})$

Pale yellow solid. Yield 74\%. M.p. $112-114^{\circ} \mathrm{C}$. FT-IR (KBr): $v$ 3067, 1675, 1501, 1219, $765 \mathrm{~cm}^{-1} .{ }^{1} \mathrm{H}$ NMR (300 $\left.\mathrm{MHz}, \mathrm{CDCl}_{3}\right): \delta 12.00(\mathrm{~s}, 1 \mathrm{H}, \mathrm{ArOH}), 8.43(\mathrm{~s}, 1 \mathrm{H}$, pyrazole $\left.\mathrm{H}_{3}\right), 8.17\left(\mathrm{~s}, 1 \mathrm{H}\right.$, pyrazole $\left.\mathrm{H}_{5}\right), 7.91\left(\mathrm{dd}, J_{1}=8.1 \mathrm{~Hz}, J_{2}=1.7\right.$ $\mathrm{Hz}, 1 \mathrm{H}, \mathrm{Ar}-\mathrm{H}), 7.75-7.70(\mathrm{~m}, 2 \mathrm{H}, \mathrm{Ar}-\mathrm{H}), 7.53\left(\mathrm{td}, 1 \mathrm{H}, J_{1}=\right.$ $\left.7.3 \mathrm{~Hz}, J_{2}=1.7 \mathrm{~Hz}, \mathrm{Ar}-\mathrm{H}\right), 7.21(\mathrm{t}, 2 \mathrm{H}, J=9.0 \mathrm{~Hz}, \mathrm{Ar}-\mathrm{H})$, $7.07\left(\mathrm{dd}, J_{1}=8.4 \mathrm{~Hz}, J_{2}=1.2 \mathrm{~Hz}, 1 \mathrm{H}, \mathrm{Ar}-\mathrm{H}\right), 6.98(\mathrm{dt}, 1 \mathrm{H}$, $\left.J_{1}=8.1 \mathrm{~Hz}, J_{2}=1.1 \mathrm{~Hz}, \mathrm{Ar}-\mathrm{H}\right) .{ }^{13} \mathrm{C} \mathrm{NMR}\left(75 \mathrm{MHz}, \mathrm{CDCl}_{3}\right)$ : $\delta 191.9,162.6,160.2,142.3,136.0,135.4,131.1,130.5$, $123.4,121.7,121.6,120.0,119.0,118.5,116.7,116.4$. ESI-MS: $m / z[\mathrm{M}+\mathrm{H}]^{+} 283$.

(1-(4-Bromophenyl)-1H-pyrazol-4-yl)(2-hydroxyphenyl)methanone (6h)

Pale yellow solid. Yield $68 \%$. M.p. $115-117^{\circ} \mathrm{C}$. FT-IR

(KBr): $v$ 3112, 2924, 1626, 1542, 1243, 905, $756 \mathrm{~cm}^{-1} .{ }^{1} \mathrm{H}$
NMR (300 MHz, $\left.\mathrm{CDCl}_{3}\right): \delta 11.98(\mathrm{~s}, 1 \mathrm{H}, \mathrm{ArOH}), 8.46(\mathrm{~s}$, $1 \mathrm{H}$, pyrazole $\left.\mathrm{H}_{3}\right), 8.18\left(\mathrm{~s}, 1 \mathrm{H}\right.$, pyrazole $\left.\mathrm{H}_{5}\right), 7.90\left(\mathrm{dd}, J_{1}=\right.$ $\left.7.9 \mathrm{~Hz}, J_{2}=1.3 \mathrm{~Hz}, 1 \mathrm{H}, \mathrm{Ar}-\mathrm{H}\right), 7.65(\mathrm{~s}, 4 \mathrm{H}, \mathrm{Ar}-\mathrm{H}), 7.54$ (td, $\left.1 \mathrm{H}, J_{1}=8.4 \mathrm{~Hz}, J_{2}=1.3 \mathrm{~Hz}, \mathrm{Ar}-\mathrm{H}\right), 7.08(\mathrm{~d}, 1 \mathrm{H}, J=8.3 \mathrm{~Hz}$, Ar-H), $6.98(\mathrm{t}, 1 \mathrm{H}, J=7.9 \mathrm{~Hz}, \mathrm{Ar}-\mathrm{H}) .{ }^{13} \mathrm{C}$ NMR $(75 \mathrm{MHz}$, $\left.\mathrm{CDCl}_{3}\right): \delta 191.9,162.6,142.5,138.0,136.1,132.7,131.0$, $130.2,121.0,119.0,118.5$.

(2-Hydroxy-5-methylphenyl)(1-m-tolyl-1H-pyrazol-4yl)methanone (6i)

Yellow thick liquid. Yield 73\%. FT-IR (KBr): $v 3127$, $1629,1541,1227,783 \mathrm{~cm}^{-1} .{ }^{1} \mathrm{H}$ NMR $\left(300 \mathrm{MHz}, \mathrm{CDCl}_{3}\right): \delta$ $11.82(\mathrm{~s}, 1 \mathrm{H}, \mathrm{ArOH}), 8.45\left(\mathrm{~s}, 1 \mathrm{H}\right.$, pyrazole $\left.\mathrm{H}_{3}\right), 8.16(\mathrm{~s}, 1 \mathrm{H}$, pyrazole $\left.\mathrm{H}_{5}\right), 7.68(\mathrm{~d}, J=1.3 \mathrm{~Hz}, 1 \mathrm{H}, \mathrm{Ar}-\mathrm{H}), 7.58(\mathrm{~d}, J=1.5$ $\mathrm{Hz}, 1 \mathrm{H}, \mathrm{Ar}-\mathrm{H}), 7.51(\mathrm{~d}, J=7.9 \mathrm{~Hz}, 1 \mathrm{H}, \mathrm{Ar}-\mathrm{H}), 7.39(\mathrm{t}, J=$ $7.7 \mathrm{~Hz}, 1 \mathrm{H}, \mathrm{Ar}-\mathrm{H}), 7.33\left(\mathrm{dd}, J_{1}=8.6 \mathrm{~Hz}, J_{2}=2.2 \mathrm{~Hz}, 1 \mathrm{H}\right.$, Ar-H), 7.19 (d, $J=7.5 \mathrm{~Hz}, 1 \mathrm{H}, \mathrm{Ar}-\mathrm{H}), 6.97(\mathrm{~d}, J=8.4 \mathrm{~Hz}$, $1 \mathrm{H}, \mathrm{Ar}-\mathrm{H}), 2.44\left(\mathrm{~s}, 3 \mathrm{H}, \mathrm{CH}_{3}\right), 2.34\left(\mathrm{~s}, 3 \mathrm{H}, \mathrm{CH}_{3}\right) .{ }^{13} \mathrm{C} \mathrm{NMR}$ $\left(75 \mathrm{MHz}, \mathrm{CDCl}_{3}\right): \delta 192.0,160.4,142.1,139.8,139.0$, $136.9,130.9,130.3,129.3,128.5,128.0,123.2,120.4,119.7$, 118.1, 116.7, 21.3, 20.5. ESI-MS: $m / z[\mathrm{M}+\mathrm{H}]^{+} 293$.

\section{(2-Hydroxy-5-methylphenyl)(1-(4-methoxyphenyl)-1H -pyrazol-4-yl)methanone (6j)}

Yellow solid. Yield $61 \%$. M.p. $128-130{ }^{\circ} \mathrm{C}$. FT-IR (KBr): v 3131, 1585, 1539, $1225 \mathrm{~cm}^{-1} .{ }^{1} \mathrm{H}$ NMR $(300 \mathrm{MHz}$, $\left.\mathrm{CDCl}_{3}\right): \delta 11.83(\mathrm{~s}, 1 \mathrm{H}, \mathrm{ArOH}), 8.38\left(\mathrm{~s}, 1 \mathrm{H}\right.$, pyrazole $\left.\mathrm{H}_{3}\right)$, $8.14\left(\mathrm{~s}, 1 \mathrm{H}\right.$, pyrazole $\left.\mathrm{H}_{5}\right), 7.69(\mathrm{~d}, 1 \mathrm{H}, J=1.2 \mathrm{~Hz}, \mathrm{Ar}-\mathrm{H})$, $7.64(\mathrm{~d}, 2 \mathrm{H}, J=9.0 \mathrm{~Hz}, \mathrm{Ar}-\mathrm{H}), 7.33\left(\mathrm{dd}, 1 \mathrm{H}, J_{1}=8.3 \mathrm{~Hz}, J_{2}\right.$ $=1.5 \mathrm{~Hz}, \operatorname{Ar}-\mathrm{H}), 7.03(\mathrm{~d}, 2 \mathrm{H}, J=9.0 \mathrm{~Hz}, \operatorname{Ar}-\mathrm{H}), 6.97(\mathrm{~d}$, $1 \mathrm{H}, J=8.3 \mathrm{~Hz}, \mathrm{Ar}-\mathrm{H}), 3.86\left(\mathrm{~s}, 3 \mathrm{H}, \mathrm{OCH}_{3}\right), 2.34(\mathrm{~s}, 1 \mathrm{H}$, $\left.\mathrm{CH}_{3}\right) .{ }^{13} \mathrm{C}$ NMR $\left(75 \mathrm{MHz}, \mathrm{CDCl}_{3}\right): \delta 192.0,160.4,159.1$, $142.0,136.9,132.7,130.9,130.3,128.1,123.1,121.3,119.7$, 118.2, 114.6, 55.5, 20.5. ESI-MS: $m / z[\mathrm{M}+\mathrm{H}]^{+} 309$.

(1-(2-Fluorophenyl)-1H-pyrazol-4-yl)(2-hydroxy-5-methylphenyl)methanone (6k)

Pale yellow solid. Yield $73 \%$. M.p. $115-117^{\circ} \mathrm{C}$. FT-IR $(\mathrm{KBr}): v 3063,1630,1592,1230,757 \mathrm{~cm}^{-1} .{ }^{1} \mathrm{H}$ NMR $(300$ $\left.\mathrm{MHz}, \mathrm{CDCl}_{3}\right): \delta 11.80(\mathrm{~s}, 1 \mathrm{H}, \mathrm{ArOH}), 8.54(\mathrm{~d}, J=2.2 \mathrm{~Hz}$, $1 \mathrm{H}$, pyrazole $\left.\mathrm{H}_{3}\right), 8.20\left(\mathrm{~s}, 1 \mathrm{H}\right.$, pyrazole $\left.\mathrm{H}_{5}\right), 7.94\left(\mathrm{dt}, 1 \mathrm{H}, J_{1}\right.$ $\left.=8.4 \mathrm{~Hz}, J_{2}=2.0 \mathrm{~Hz}, \mathrm{Ar}-\mathrm{H}\right), 7.68(\mathrm{~d}, J=1.3 \mathrm{~Hz}, 1 \mathrm{H}, \mathrm{Ar}-\mathrm{H})$, 7.42-7.28 (m, 4H, Ar-H), 6.97 (d, $1 \mathrm{H}, J=8.4 \mathrm{~Hz}, \mathrm{Ar}-\mathrm{H})$, $2.34\left(\mathrm{~s}, 3 \mathrm{H}, \mathrm{CH}_{3}\right) .{ }^{13} \mathrm{C}$ NMR $\left(75 \mathrm{MHz}, \mathrm{CDCl}_{3}\right): \delta 191.9$, $160.4,151.8,142.0,137.0,134.3,134.1,130.9,129.0,128.1$, $125.1,124.5,119.6,118.1,117.0,116.8,20.5$. ESI-MS: $m / z$ $[\mathrm{M}+\mathrm{H}]^{+} 297$.

( 1 - (3-Fluorophenyl) - $1 H$-pyrazol-4-yl) (2-hydroxy-5-methylphenyl)methanone (61)

Yellow solid. Yield $82 \%$. M.p. $136-138{ }^{\circ} \mathrm{C}$. FT-IR (KBr): $v 3141,1630,1543,1228,759 \mathrm{~cm}^{-1} .{ }^{1} \mathrm{H}$ NMR $(300$ $\left.\mathrm{MHz}, \mathrm{CDCl}_{3}\right): \delta 11.77(\mathrm{~s}, 1 \mathrm{H}, \mathrm{ArOH}), 8.48(\mathrm{~s}, 1 \mathrm{H}$, pyrazole $\left.\mathrm{H}_{3}\right), 8.17\left(\mathrm{~s}, 1 \mathrm{H}\right.$, pyrazole $\left.\mathrm{H}_{5}\right), 7.67(\mathrm{~d}, J=1.3 \mathrm{~Hz}, 1 \mathrm{H}, \mathrm{Ar}-$ $\mathrm{H}), 7.58-7.46(\mathrm{~m}, 3 \mathrm{H}, \mathrm{Ar}-\mathrm{H}), 7.35\left(\mathrm{dd}, J_{1}=8.4 \mathrm{~Hz}, J_{2}=2.0\right.$ $\mathrm{Hz}, 1 \mathrm{H}, \mathrm{Ar}-\mathrm{H}), 7.14-7.06$ (m, 1H, Ar-H), 6.99 (d, J = 8.3 
$\mathrm{Hz}, 1 \mathrm{H}, \mathrm{Ar}-\mathrm{H}), 2.35$ (s, 3H, $\left.\mathrm{CH}_{3}\right) \cdot{ }^{13} \mathrm{C}$ NMR $(75 \mathrm{MHz}$, $\mathrm{CDCl}_{3}$ ): $\delta 191.9,164.8,160.5,142.5,137.2,131.1,130.9$, 130.8, 130.3, 128.2, 119.6, 118.3, 114.7, 114.5, 107.7, 107.3, 20.6. ESI-MS: $m / z[\mathrm{M}+\mathrm{H}]^{+} 297$.

(1-(4-Fluorophenyl)-1H-pyrazol-4-yl)(2-hydroxy-5methylphenyl)methanone $(6 \mathrm{~m})$

Pale yellow solid. Yield $74 \%$. M.p. $125-127^{\circ} \mathrm{C}$. FT-IR (KBr): $v$ 3120, 1631, 1583, 1222, $836 \mathrm{~cm}^{-1}$. ${ }^{1} \mathrm{H}$ NMR $(300$ $\left.\mathrm{MHz}, \mathrm{CDCl}_{3}\right): \delta 11.79(\mathrm{~s}, 1 \mathrm{H}, \mathrm{ArOH}) 8.42(\mathrm{~s}, 1 \mathrm{H}$, pyrazole $\left.\mathrm{H}_{3}\right), 8.16\left(\mathrm{~s}, 1 \mathrm{H}\right.$, pyrazole $\left.\mathrm{H}_{5}\right), 7.76-7.70(\mathrm{~m}, 2 \mathrm{H}, \mathrm{Ar}-\mathrm{H})$, $7.67(\mathrm{~d}, 1 \mathrm{H}, J=1.2 \mathrm{~Hz}, \mathrm{Ar}-\mathrm{H}), 7.34\left(\mathrm{dd}, J_{1}=8.3 \mathrm{~Hz}, J_{2}=1.9\right.$ $\mathrm{Hz}, 1 \mathrm{H}, \mathrm{Ar}-\mathrm{H}), 7.21$ (t, $2 \mathrm{H}, J=8.1 \mathrm{~Hz}, \mathrm{Ar}-\mathrm{H}), 6.97(\mathrm{~d}, 1 \mathrm{H}$, $J=8.4 \mathrm{~Hz}, \mathrm{Ar}-\mathrm{H}), 2.34\left(\mathrm{~s}, 3 \mathrm{H}, \mathrm{CH}_{3}\right) \cdot{ }^{13} \mathrm{C}$ NMR $(75 \mathrm{MHz}$, $\left.\mathrm{CDCl}_{3}\right): \delta 191.9,160.5,142.3,137.1,135.4,130.8,130.4$, $128.1,123.5,121.5,119.6,118.2,116.6,116.3,20.5$. ESIMS: $m / z[\mathrm{M}+\mathrm{H}]^{+} 297$.

\section{(1-(4-Bromophenyl)-1H-pyrazol-4-yl)(2-hydroxy-5- methylphenyl)methanone (6n)}

Pale yellow solid. Yield $82 \%$. M.p. $142-144^{\circ} \mathrm{C}$. FTIR (KBr): $v 3132,1592,1539,1229 \mathrm{~cm}^{-1} .{ }^{1} \mathrm{H}$ NMR (300 $\mathrm{MHz}, \mathrm{CDCl}_{3}$ ): $\delta 11.77(\mathrm{~s}, 1 \mathrm{H}, \mathrm{ArOH}), 8.46(\mathrm{~s}, 1 \mathrm{H}$, pyrazole $\left.\mathrm{H}_{3}\right), 8.17\left(\mathrm{~s}, 1 \mathrm{H}\right.$, pyrazole $\left.\mathrm{H}_{5}\right), 7.65(\mathrm{brs}, 5 \mathrm{H}, \mathrm{Ar}-\mathrm{H})$, $7.35\left(\mathrm{dd}, 1 \mathrm{H}, J_{1}=8.4 \mathrm{~Hz}, J_{2}=2.0 \mathrm{~Hz}, \mathrm{Ar}-\mathrm{H}\right), 6.98(\mathrm{~d}, 1 \mathrm{H}$, $J=8.4 \mathrm{~Hz}, \mathrm{Ar}-\mathrm{H}), 2.34\left(\mathrm{~s}, 3 \mathrm{H}, \mathrm{CH}_{3}\right) .{ }^{13} \mathrm{C} \mathrm{NMR}(75 \mathrm{MHz}$, $\left.\mathrm{CDCl}_{3}\right): \delta 191.8,160.5,142.4,138.1,137.1,132.7,130.8$, $130.1,128.1,123.7,115.0,119.6,118.2,20.5$. ESI-MS: $m / z$ $[\mathrm{M}+\mathrm{H}]^{+} 357$.

\section{(5-Chloro-2-hydroxyphenyl)(1-phenyl-1H-pyrazol-4- yl)methanone (6o)}

Pale yellow solid. Yield $67 \%$. M.p. $142-144^{\circ} \mathrm{C}$. FT-IR (KBr): $v 3127,1581,1464,1215,752 \mathrm{~cm}^{-1} .{ }^{1} \mathrm{H}$ NMR (300 $\left.\mathrm{MHz}, \mathrm{CDCl}_{3}\right): \delta 11.90(\mathrm{~s}, 1 \mathrm{H}, \mathrm{ArOH}), 8.50(\mathrm{~s}, 1 \mathrm{H}$, pyrazole $\left.\mathrm{H}_{3}\right), 8.20\left(\mathrm{~s}, 1 \mathrm{H}\right.$, pyrazole $\left.\mathrm{H}_{5}\right), 7.88(\mathrm{~d}, 1 \mathrm{H}, J=2.2 \mathrm{~Hz}$, Ar-H), 7.76 (d, 2H, $J=7.5 \mathrm{~Hz}, \mathrm{Ar}-\mathrm{H}), 7.57-7.39(\mathrm{~m}, 4 \mathrm{H}$, Ar-H), 7.04 (d, $1 \mathrm{H}, J=9.0 \mathrm{~Hz}, \mathrm{Ar}-\mathrm{H}) .{ }^{13} \mathrm{C}$ NMR $(75 \mathrm{MHz}$, $\left.\mathrm{CDCl}_{3}\right): \delta 190.9,161.0,142.2,139.0,135.8,130.4,130.2$, 129.6, 128.0, 123.7, 122.8, 120.6, 120.1, 119.8. ESI-MS: $m / z$ $[\mathrm{M}+\mathrm{H}]^{+} 299$.

(5-Chloro-2-hydroxyphenyl)(1-m-tolyl-1H-pyrazol-4yl)methanone (6p)

Yellow solid. Yield $81 \%$. M.p. $105-107{ }^{\circ} \mathrm{C}$. FT-IR (KBr): v3127, 1624, 1539, $1228 \mathrm{~cm}^{-1} .{ }^{1} \mathrm{H}$ NMR $(300 \mathrm{MHz}$, $\left.\mathrm{CDCl}_{3}\right): \delta 11.90(\mathrm{~s}, 1 \mathrm{H}, \mathrm{ArOH}), 8.47\left(\mathrm{~s}, 1 \mathrm{H}\right.$, pyrazole $\left.\mathrm{H}_{3}\right)$, $8.18\left(\mathrm{~s}, 1 \mathrm{H}\right.$, pyrazole $\left.\mathrm{H}_{5}\right), 7.87(\mathrm{~d}, 1 \mathrm{H}, J=2.4 \mathrm{~Hz}, \mathrm{Ar}-\mathrm{H})$, $7.59(\mathrm{~d}, J=1.5 \mathrm{~Hz}, 1 \mathrm{H}, \mathrm{Ar}-\mathrm{H}), 7.53(\mathrm{~d}, 1 \mathrm{H}, J=8.1 \mathrm{~Hz}, \mathrm{Ar}-$ $\mathrm{H}), 7.46\left(\mathrm{dd}, 1 \mathrm{H}, J_{1}=8.8 \mathrm{~Hz}, J_{2}=2.6 \mathrm{~Hz}, \operatorname{Ar}-\mathrm{H}\right), 7.40(\mathrm{t}$, $1 \mathrm{H}, J=7.7 \mathrm{~Hz}$, Ar-H), 7.62-7.51 (m, 3H, Ar-H), $7.40(\mathrm{t}$, $1 \mathrm{H}, J=7.7 \mathrm{~Hz}$, Ar- $\mathrm{H}), 7.22(\mathrm{~d}, 1 \mathrm{H}, J=7.5 \mathrm{~Hz}, \mathrm{Ar}-\mathrm{H}), 7.03$ $(\mathrm{d}, 1 \mathrm{H}, J=8.8 \mathrm{~Hz}, \mathrm{Ar}-\mathrm{H}), 2.46\left(\mathrm{~s}, 1 \mathrm{H}, \mathrm{CH}_{3}\right) \cdot{ }^{13} \mathrm{C}$ NMR $(75$ $\left.\mathrm{MHz}, \mathrm{CDCl}_{3}\right): \delta 190.9,161.0,142.1,139.8,138.8,135.7$, 130.4, 130.1, 129.4, 128.7, 123.7, 122.6, 120.5, 120.0, 116.8, 21.4. ESI-MS: $m / z[\mathrm{M}+\mathrm{H}]^{+313}$.
(5-Chloro-2-hydroxyphenyl)(1-(4-methoxyphenyl)-1H -pyrazol-4-yl)methanone (6q)

Yellow thick liquid. Yield 87\%. FT-IR (KBr): $v$ 3232, 1584, 1517, 1219, $773 \mathrm{~cm}^{-1} .{ }^{1} \mathrm{H}$ NMR $\left(300 \mathrm{MHz}, \mathrm{CDCl}_{3}\right): \delta$ $11.91(\mathrm{~s}, 1 \mathrm{H}, \mathrm{ArOH}), 8.39\left(\mathrm{~s}, 1 \mathrm{H}\right.$, pyrazole $\left.\mathrm{H}_{3}\right), 8.16(\mathrm{~s}, 1 \mathrm{H}$, pyrazole $\left.\mathrm{H}_{5}\right), 7.87(\mathrm{~d}, J=3.0 \mathrm{~Hz}, 1 \mathrm{H}, \mathrm{Ar}-\mathrm{H}), 7.65(\mathrm{~d}, 2 \mathrm{H}, J$ $=9.0 \mathrm{~Hz}, \mathrm{Ar}-\mathrm{H}), 7.46\left(\mathrm{dd}, 1 \mathrm{H}, J_{1}=8.3 \mathrm{~Hz}, J_{2}=2.2 \mathrm{~Hz}\right.$, Ar-H), $7.02(\mathrm{~d}, 3 \mathrm{H}, J=9.0 \mathrm{~Hz}, \mathrm{Ar}-\mathrm{H}), 3.87\left(\mathrm{~s}, 3 \mathrm{H}, \mathrm{OCH}_{3}\right)$. ${ }^{13} \mathrm{C}$ NMR $\left(75 \mathrm{MHz}, \mathrm{CDCl}_{3}\right): \delta 191.0,161.0,159.3,142.0$, 135.7, 132.6, 130.4, 130.2, 123.7, 122.6, 121.5, 120.1, 114.7, 55.6. ESI-MS: $m / z[\mathrm{M}+\mathrm{H}]^{+} 329$.

(5-Bromo-2-hydroxyphenyl)(1-m-tolyl-1H-pyrazol-4yl)methanone (6r)

Pale yellow solid. Yield $68 \%$. M.p. $122-124^{\circ} \mathrm{C}$. FT-IR (KBr): $v 3118,1630,1542,1225,823 \mathrm{~cm}^{-1} .{ }^{1} \mathrm{H}$ NMR (300 $\left.\mathrm{MHz}, \mathrm{CDCl}_{3}\right): \delta 11.91(\mathrm{~s}, 1 \mathrm{H}, \mathrm{ArOH}), 8.47(\mathrm{~s}, 1 \mathrm{H}$, pyrazole $\left.\mathrm{H}_{3}\right), 8.17\left(\mathrm{~s}, 1 \mathrm{H}\right.$, pyrazole $\left.\mathrm{H}_{5}\right), 8.01(\mathrm{~d}, 1 \mathrm{H}, J=2.2 \mathrm{~Hz}$, Ar-H), 7.62-7.51 (m, 3H, Ar-H), $7.40(\mathrm{t}, 1 \mathrm{H}, J=7.7 \mathrm{~Hz}$, $\operatorname{Ar}-\mathrm{H}), 6.98(\mathrm{~d}, 1 \mathrm{H}, J=8.8 \mathrm{~Hz}, \mathrm{Ar}-\mathrm{H}), 2.46\left(\mathrm{~s}, 1 \mathrm{H}, \mathrm{CH}_{3}\right)$. ${ }^{13} \mathrm{C}$ NMR $\left(75 \mathrm{MHz}, \mathrm{CDCl}_{3}\right): \delta 190.9,161.4,142.1,139.9$, $138.9,138.5,133.2,130.5,129.4,128.8,122.6,121.2,120.4$, 116.8, 110.6, 21.4. ESI-MS: $m / z[\mathrm{M}+\mathrm{H}]^{+} 357$.

(5-Bromo-2-hydroxyphenyl)(1-(4-methoxyphenyl)-1Hpyrazol-4-yl)methanone (6s)

Pale yellow solid. Yield $87 \%$. M.p. $128-130^{\circ} \mathrm{C}$. FT-IR (KBr): v 3122, 1615, 1581, 1249, $818 \mathrm{~cm}^{-1} .{ }^{1} \mathrm{H}$ NMR (300 $\left.\mathrm{MHz}, \mathrm{CDCl}_{3}\right): \delta 11.93(\mathrm{~s}, 1 \mathrm{H}, \mathrm{ArOH}), 8.39(\mathrm{~s}, 1 \mathrm{H}$, pyrazole $\left.\mathrm{H}_{3}\right), 8.16\left(\mathrm{~s}, 1 \mathrm{H}\right.$, pyrazole $\left.\mathrm{H}_{5}\right), 8.02(\mathrm{~d}, J=2.2 \mathrm{~Hz}, 1 \mathrm{H}$, $\mathrm{Ar}-\mathrm{H}), 7.66(\mathrm{~d}, 2 \mathrm{H}, J=9.0 \mathrm{~Hz}, \mathrm{Ar}-\mathrm{H}), 7.60\left(\mathrm{dd}, 1 \mathrm{H}, J_{1}=9.0\right.$ $\left.\mathrm{Hz}, J_{2}=3.0 \mathrm{~Hz}, \mathrm{Ar}-\mathrm{H}\right), 7.03(\mathrm{~d}, 2 \mathrm{H}, J=9.0 \mathrm{~Hz}, \mathrm{Ar}-\mathrm{H}), 6.98$ $(\mathrm{d}, 1 \mathrm{H}, J=9.0 \mathrm{~Hz}, \mathrm{Ar}-\mathrm{H}), 3.88\left(\mathrm{~s}, 3 \mathrm{H}, \mathrm{OCH}_{3}\right) .{ }^{13} \mathrm{C} \mathrm{NMR}(75$ $\mathrm{MHz}, \mathrm{CDCl}_{3}$ ): $\delta 190.0,161.4,159.3,142.0,138.5,133.2$, $132.5,130.4,122.5,121.4,120.4,114.7,110.6,55.6$. ESI-MS: $m / z[\mathrm{M}+\mathrm{H}]^{+} 373$

(6-Hydroxybenzofuran-5-yl)(1-m-tolyl-1H-pyrazol-4yl)methanone (6t)

Yellow thick liquid. Yield 83\%. FT-IR (KBr): $v 3121$, $1634,1541,1247,785 \mathrm{~cm}^{-1}$. ${ }^{1} \mathrm{H}$ NMR $\left(300 \mathrm{MHz}, \mathrm{CDCl}_{3}\right): \delta$ $12.14(\mathrm{~s}, 1 \mathrm{H}, \mathrm{ArOH}), 8.47\left(\mathrm{~s}, 1 \mathrm{H}\right.$, pyrazole $\left.\mathrm{H}_{3}\right), 8.18(\mathrm{~s}, 1 \mathrm{H}$, pyrazole $\left.\mathrm{H}_{5}\right), 8.14(\mathrm{~s}, 1 \mathrm{H}, \mathrm{Ar}-\mathrm{H}), 7.61-7.51(\mathrm{~m}, 3 \mathrm{H}, \mathrm{Ar}-\mathrm{H})$, $7.39(\mathrm{t}, J=7.5 \mathrm{~Hz}, 1 \mathrm{H}, \operatorname{Ar}-\mathrm{H}), 7.20(\mathrm{~d}, 1 \mathrm{H}, J=7.5 \mathrm{~Hz}$, Ar-H), $6.75(\mathrm{~d}, 1 \mathrm{H}, J=1.5 \mathrm{~Hz}, \mathrm{Ar}-\mathrm{H}), 2.45\left(\mathrm{~s}, 3 \mathrm{H}, \mathrm{CH}_{3}\right) \cdot{ }^{13} \mathrm{C}$ $\operatorname{NMR}\left(75 \mathrm{MHz}, \mathrm{CDCl}_{3}\right): \delta 192.1,161.1,159.2,145.6,142.2$, 139.8, 139.1, 130.4, 129.4, 128.6, 124.6, 123.4, 120.4, 120.2, 117.4, 116.7, 106.7, 100.0, 21.4. ESI-MS: $m / z[\mathrm{M}+\mathrm{H}]^{+} 319$.

(2-Hydroxy-6-methylphenyl)(1-phenyl-1H-pyrazol-4yl)methanone (6u)

Yellow solid. Yield $77 \%$. M.p. $111-113{ }^{\circ} \mathrm{C}$. FT-IR (KBr): $v$ 3447, 1622, 1539, 1483, 1238, 903, $771 \mathrm{~cm}^{-1} .{ }^{1} \mathrm{H}$ NMR (300 MHz, CDCl $)$ : $\delta 12.13$ (s, 1H, ArOH), 8.47 (s, $1 \mathrm{H}$, pyrazole $\left.\mathrm{H}_{3}\right), 8.17\left(\mathrm{~s}, 1 \mathrm{H}\right.$, pyrazole $\left.\mathrm{H}_{5}\right), 7.80(\mathrm{~d}, 1 \mathrm{H}, J=$ $8.1 \mathrm{~Hz}, \mathrm{Ar}-\mathrm{H}), 7.75$ (d, J = 8.1 Hz, 2H, Ar-H), $7.52(\mathrm{t}, 2 \mathrm{H}, J$ 
= 7.3 Hz, Ar-H), 7.40 (d, J=7.5 Hz, 1H, Ar-H), $6.88(\mathrm{~s}, 1 \mathrm{H}$, Ar-H), 6.78 (d, J = 8.1 Hz, 1H, Ar-H), 2.39 (s, 3H, $\mathrm{CH}_{3}$ ). ${ }^{13} \mathrm{C} \mathrm{NMR}\left(75 \mathrm{MHz}, \mathrm{CDCl}_{3}\right): \delta 191.6,162.9,147.7,142.2$, 139.2, 131.1, 130.2, 129.6, 127.8, 125.0, 123.4, 120.3, 119.7, 119.5, 118.6, 117.7, 21.9. ESI-MS: $m / z[\mathrm{M}+\mathrm{H}]^{+} 279$.

\section{Anti-proliferative Assay}

\section{1. Cell Proliferation Assay}

This assay is a quantitative colorimetric method for determination of cell survival and proliferation. The assessed parameter is the metabolic activity of viable cells. ${ }^{13}$ Metabolically active cells reduce pale yellow tetrazolium salt (MTT) to a dark blue water-insoluble formazan, which can be directly quantified after solubilisation with DMSO. The absorbance of the formazan directly correlates with the number of viable cells. The cells were plated in 96-well plates at a density of $2.0 \times 104$ in $100 \mu \mathrm{L}$ of medium per well of 96 -well plate. Cultures were incubated with test compounds $(10 \mu \mathrm{M})$ and incubated for $48 \mathrm{~h}$. The medium was replaced with fresh medium containing $100 \mu \mathrm{g} / \mathrm{mL}$ of 3-(4,5-dimethylthiazol-2-yl)-2,5-diphenyltetrazolium bromide (MTT) for $2-3 \mathrm{~h}$. The supernatant was aspirated and MTT-formazan crystals dissolved in $100 \mu \mathrm{L}$ DMSO; OD measured at $\lambda 540 \mathrm{~nm}$ (reference wavelength, $\lambda 620 \mathrm{~nm}$ ) on ELISA reader cell viability \% was calculated by comparing the absorbance of treated versus untreated cells.

\section{Conclusion}

In conclusion, $4 H$-chromone-based hydrazones, pyrazolecarboxylates and pyrazolylmethanones were synthesized and evaluated for their anti-proliferative activity against four human cancer cell lines. The compounds $5 \mathbf{p}-$ $\mathbf{q}, 5 \mathbf{w}, \mathbf{6 e}$ and $\mathbf{6 j}$ displayed potent anti-proliferative activity, however, compounds $\mathbf{3} \mathbf{s}$ and $\mathbf{5 g}-\mathbf{h}$ have shown promising activity.

\section{Acknowledgments}

The authors thank Dr. S. Chandrasekhar, Director, CSIR-IICT for constant encouragement. Financial assistance to R. N. R from CSIR, New Delhi is gratefully acknowledged. B. China Raju acknowledges CSIR, New Delhi for financial support through the programme "ORIGIN" (CSC-0108) of XII five year plan.

\section{References}

1. S. Fustero, M. Sanchez-Rosello, P. Barrio, A. Simon-Fuentes, Chem. Rev. 2011, 111, 6984-7034. DOI:10.1021/cr2000459
2. S. Ulloora, R. Shabaraya, R. Ranganathan, A. V. Adhikari, Eur. J. Med. Chem. 2013, 70, 341-349.

DOI:10.1016/j.ejmech.2013.10.010

3. M. D. Altintop, A. Ozdemir, G. Turan-Zitouni, Eur. J. Med. Chem. 2012, 58, 299-307.

DOI: $10.1016 /$ j.ejmech.2012.10.011

4. A. M. Pieczonka, A. Strzelczyk, B. Sadowska, G. Mloston, P. Stączek, Eur. J. Med. Chem. 2013, 64, 389-395.

DOI:10.1016/j.ejmech.2013.04.023

5. M. B. Bhalerao, S. T. Dhumal, A. R. Deshmukh, Bioorg. Med. Chem. Lett. 2017, 27, 288-294.

DOI:10.1016/j.bmcl.2016.11.056

6. T. Yoshioka, T. Fujita, T. Kanai, Y. Aizawa, T. Kurumada, K. Hasegawa, H. Horikoshi, J. Med. Chem. 1989, 32, 421-428. DOI: $10.1021 / \mathrm{jm} 00122 \mathrm{a} 022$

7. M. Rinaldi-Carmona, F. Barth, M. Heaulme, D. Shire, B. Calandra, C. Congy, S. Martinez, J. Maruani, G. Neliat, D. Caput, P. Ferrara, P. Soubrie, J. C. Breliere, G. Le Fur, FEBS Lett. 1994, 350, 240-244.

DOI:10.1016/0014-5793(94)00773-X

8. Ch. Dayakar, B. S. Kumar, G. Sneha, G. Sagarika, K. Meghana, S. Ramakrishna, R. S. Prakasham, B. C. Raju, Bioorg. Med. Chem. 2017, 25, 5678-5691.

DOI: $10.1016 /$ j.bmc.2017.08.042

9. B. C. Raju, A. K. Tiwari, J. A. Kumar, A. Z. Ali, Sachin B. Agawane, G. Saidachary, K. Madhusudana, Bioorg. Med. Chem. 2010, 18, 358-365. DOI:10.1016/j.bmc.2009.10.047

10. G. Saidachary, K. Veera Prasad, D. Divya, A. Singh, U. Ramesh, B. Sridhar, B. C. Raju, Eur. J. Med. Chem. 2014, 76, 460-469. DOI:10.1016/j.ejmech.2014.02.042

11. P. Suman, T. R. Murthy, K. Rajkumar, D. Srikanth, Ch. Dayakar, C. Kishor, A. Addlagatta, S. V. Kalivendi, B. C. Raju, Eur. J. Med. Chem. 2015, 90, 603-619.

DOI:10.1016/j.ejmech.2014.11.063

12. P. Suman, Ch. Dayakar, K. Rajkumar, B. Yashwanth, P. Yogeeswari, D. Sriram, J. V. Rao, B. C. Raju, Bioorg. Med. Chem. Lett. 2015, 25, 2390-2394.

DOI: 10.1016/j.bmcl.2015.04.009

13. B. C. Raju, R. N. Rao, P. Suman, P. Yogeeswari, D. Sriram, T. B. Shaik, S. V. Kalivendi, Bioorg. Med. Chem. Lett. 2011, 21, 2855-2859. http://doi.org/10.1016/j.bmcl.2011.03.079

14. K. Rajkumar, P. Suman, B. C. Raju, RSC Adv. 2015, 5, 7385073858. DOI: $10.1039 / \mathrm{c} 5 \mathrm{ra} 10185 \mathrm{a}$

15. W. Guangcheng, C. Ming, W. Jing, P. Yaping, L. Luyao, Z. X. Zhen, D. Bing, C. Shan, L. Wenbiao, Bioorg. Med. Chem. Lett. 2017, 27, 2957-2961. DOI:10.1016/j.bmcl.2017.05.007

16. L. Deng, W. Wang, C. Hu, C. Wu, CN103554123, 2016.

17. L. Deng, W. Wang, G. Chen, Q. Yang, X. Gao, Y. Zhou, C. Hu, C. Wu, R. Shen, Y. Wu, CN106083884, 2016.

18. A. Lazarenkow, J. Nawrot-Modranka, E. Brzezinska, U. Krajewska, M. Rozalski, Med. Chem. Res. 2012, 21, 1861-1868. DOI:10.1007/s00044-011-9703-4

19. B. A. Kumar, P. Dipak, S. J. Singh, Tetrahedron 1988, 44, 1241-1246. DOI:10.1016/S0040-4020(01)85904-4

20. M. A. Ibrahim, N. M. El-Gohary, Heterocycles 2014, 89, 413425. DOI:10.3987/COM-13-12899 


\section{Povzetek}

Sintetizirali smo serijo hidrazonov 3a-z, pirazolkarboksilatov $\mathbf{5 a - x}$ in pirazolilmetanonov $\mathbf{6 a}-\mathbf{u}$, temelječih na ogrodju $4 H$-kromona. Za vse pripravljene spojine smo preučili anti-proliferativne lastnosti proti celičnim linijam A549, HeLa, DU145 in MDAMB 231. Hidrazon 3s s kloro substituentom na kromanonskem skeletu in z metoksi skupino na fenilnem obroču je izkazoval obetavno aktivnost na celične linije A549, HeLa in DU145. Spojina 5p z bromo substituentom na kromanonskem skeletu in metilno skupino na fenilnem obroču je izkazala veliko aktivnost proti celični liniji DU145. Furopirazolkarboksilat $\mathbf{5 w}$, ki vsebuje metilni substituent na fenilnem obroču, je izkazal močno aktivnost proti HeLa celični liniji. Pirazolilmetanon $\mathbf{6 e} \mathrm{s}$ fluoro substituentom na fenilnem obroču in spojina $\mathbf{6 j} \mathrm{z}$ metilnim substituentom na kromanonskem skeletu ter metoksi skupino na fenilnem obroču sta izkazali obetavne anti-proliferativne lastnosti proti HeLa celični liniji. 